\title{
Reconstructing atmospheric circulation and sea-ice extent in the West Antarctic over the past 200 years using data assimilation
}

Quentin Dalaiden ( $\sim$ quentin.dalaiden@uclouvain.be )

Université Catholique de Louvain https://orcid.org/0000-0002-3885-3848

Hugues Goosse

Université Catholique de Louvain

Jeanne Rezsohazy

Université Catholique de Louvain

Elizabeth R. Thomas

British Antarctic Survey

\section{Research Article}

Keywords: climate reconstruction, Antarctic, ice cores, climate models, data assimilation

Posted Date: May 27th, 2021

DOI: https://doi.org/10.21203/rs.3.rs-224001/v1

License: (c) This work is licensed under a Creative Commons Attribution 4.0 International License.

Read Full License

Version of Record: A version of this preprint was published at Climate Dynamics on July 13th, 2021. See the published version at https://doi.org/10.1007/s00382-021-05879-6. 


\title{
Reconstructing atmospheric circulation and sea-ice extent in the West Antarctic over the past 200 years using data assimilation
}

\author{
Quentin Dalaiden - Hugues Goosse • \\ Jeanne Rezsöhazy · Elizabeth R. Thomas
}

Received: date / Accepted: date

\begin{abstract}
The West Antarctic climate has witnessed large changes during the second half of the $20^{\text {th }}$ century including a strong and widespread continental warming, important regional changes in sea-ice extent and snow accumulation, as well as a major mass loss from the melting of some ice shelves. However, the potential links between those observed changes are still unclear and instrumental data do not allow determination of whether they are part of a long-term evolution or specific to the recent decades. In this study, we analyze the climate variability of the past two centuries in the West Antarctic sector by reconstructing the key atmospheric variables (atmospheric circulation, near-surface air temperature and snow accumulation) as well as the sea-ice extent at the annual timescale using a data assimilation approach. To this end, information from Antarctic ice core records (snow accumulation and $\left.\delta^{18} \mathrm{O}\right)$ and tree-ring width records situated in the mid-latitudes of the Southern Hemisphere are combined with the physics of climate models using a data
\end{abstract}

Q. Dalaiden

Université catholique de Louvain (UCLouvain), Earth and Life Institute (ELI), Georges Lemaître Centre for Earth and Climate Research (TECLIM), Place Louis Pasteur, B-1348 Louvain-la-Neuve, Belgium

E-mail: quentin.dalaiden@uclouvain.be

H. Goosse

Université catholique de Louvain (UCLouvain), Earth and Life Institute (ELI), Georges Lemaître Centre for Earth and Climate Research (TECLIM), Place Louis Pasteur, B-1348 Louvain-la-Neuve, Belgium

J. Rezsöhazy

Université catholique de Louvain (UCLouvain), Earth and Life Institute (ELI), Georges Lemaître Centre for Earth and Climate Research (TECLIM), Place Louis Pasteur, B-1348 Louvain-la-Neuve, Belgium

Aix Marseille University, CNRS, IRD, INRA, College de France, CEREGE, Aix-en-Provence, France

E.R. Thomas

British Antarctic Survey, Madingley Road, Cambridge, CB3 0ET, UK 
assimilation method. This ultimately provides a complete spatial reconstruction over the West Antarctic region. Our reconstruction reproduces well the main characteristics of the observed changes over the instrumental period. We show that the observed sea-ice reduction in the Bellingshausen-Amundsen Sea sector over the satellite era is part of a long-term trend, starting at around $1850 \mathrm{CE}$, while the sea-ice expansion in the Ross Sea sector has only started around 1950 CE. Furthermore, according to our reconstruction, the Amundsen Sea Low pressure (ASL) displays no significant linear trend in its strength or position over 1850-1950 CE but becomes stronger and shifts eastward afterwards. The year-to-year sea-ice variations in the Ross Sea sector are strongly related to the ASL variability over the past two centuries, including the recent trends. By contrast, the link between ASL and sea-ice in the BellingshausenAmundsen Sea sector changes with time, being stronger in recent decades than before. Our reconstruction also suggests that the continental response to the variability of the ASL may not be stationary over time, being significantly affected by modification of the mean circulation. Finally, we show that the widespread warming since $1958 \mathrm{CE}$ in West Antarctica is unusual in the context of past 200 years and is explained by both the deeper ASL and the positive phase of the Southern Annular Mode.

Keywords climate reconstruction · Antarctic · ice cores · climate models . data assimilation

\section{Introduction}

The Antarctic Ice Sheet is the biggest reservoir of fresh water on Earth that would potentially raise the global sea-level by $58 \mathrm{~m}$ if the entire ice sheet melted (Shepherd et al., 2018). Despite the remote location, the Antarctic and the Southern Ocean have experienced major climate changes over the past decades (e.g., Jones et al., 2019, Bromwich et al., 2013, Medley and Thomas, 2019, Pritchard et al. | 2012), demonstrating large variability and their vulnerability to the global climate change.

The largest changes have been found over the Antarctic Peninsula and the West Antarctic Ice Sheet (hereafter WAIS) (e.g., Jones et al., 2019), together forming West Antarctica. A major warming has been observed since the International Geophysical Year (i.e., $1958 \mathrm{CE}$ ), far exceeding the global warming during the same period (Vaughan et al., 2003, Turner et al., 2005a; Nicolas and Bromwich, 2014). Although the warming is particularly pronounced over the Peninsula, the warming over the central WAIS since the 1950s is one of the fastest recorded on Earth (Steig et al., 2009 Bromwich et al., 2013). Moreover, in the last decades, glaciers from West Antarctica (especially the Thwaites and Pine Island glaciers) have been losing mass at the ocean-ice shelf (i.e., the floating part of the glacier) interface at an accelerated rate (Pritchard et al., 2012 Rignot et al., 2019). This ice shelf melting positively contributes to the global sea-level rise, by directly enhancing the ice flow to the Southern Ocean. In contrast with these spatially homogeneous changes, snow accumulation integrated 
over West Antarctica has increased at an increased pace over the $20^{\text {th }}$ century, but with strong regional differences (Medley and Thomas, 2019, Wang et al. 2019). While the Antarctic Peninsula and the Eastern WAIS have gained mass at the surface through snow accumulation, the Western WAIS has displayed a snow accumulation decrease (Medley and Thomas, 2019, Wang et al., 2019). Additionally, a large reduction of the sea-ice extent has been noticed in the Bellingshausen/Amundsen Sea sector that contrasts with an expansion in the Ross Sea sector over the satellite era (starting from 1979 CE) (Parkinson. 2019).

The observed changes in West Antarctica are not independent of each other, and have been widely attributed to changes in atmospheric circulation (e.g., Bromwich et al., 2013; Thomas et al., 2013; Steig et al., 2013), characterized by an increase in the intensity and a poleward shift of the westerly winds (Westerlies) (Marshall, 2003). This has been observed as a deepening in the Amundsen Sea Low (ASL), a quasi-stationary low-pressure system located off the Amundsen coast (hereafter ASL) (e.g., Raphael et al., 2016). Due to its location, variations in both the strength and position of the ASL strongly modulate the West Antarctic climate (e.g., Hosking et al. 2013). For instance, a stronger ASL enhances the northerly flow (onshore winds) to the continent, which warms the Antarctic Peninsula and the eastern WAIS (e.g., Hosking et al. 2013) and increases snow accumulation (Turner et al., 2005b; Thomas et al. 2008). At the same time a stronger ASL enhances the southerly flow (offshore winds) of cold dry air masses over the western WAIS leading to lower temperatures and reduced snow accumulation. In addition to continental changes, a stronger ASL is also associated with reduced sea-ice cover in the Bellingshausen/Amundsen Sea sector and a sea-ice cover expansion in the Ross Sea sector (e.g., Raphael and Hobbs, 2014). A deeper ASL also drives oceanic changes, enhancing warm ocean water upwelling towards ice shelves, inducing basal melting (e.g., Mankoff et al., 2012; Dotto et al., 2020).

The ASL is thus a major feature of the atmospheric circulation in the Southern Hemisphere, which displays one of the greatest year-to-year variations on Earth (e.g., Turner et al., 2019). The ASL is strongly modulated by the atmospheric circulation of the high latitudes of the Southern Hemisphere. Particularly, the Southern Annular Mode (hereafter SAM) describes the latitudinal movement of the Westerlies as well as their strength (e.g., Fogt and Marshall, 2020). When the SAM is in its positive phase, the Westerlies are stronger and located further south than in the negative phase, which in turn deepens the ASL (e.g., Raphael et al. 2016). The ASL is thus strongly related to the SAM. Wind changes in the West Antarctic are also closely linked to the climate variability in tropical oceanic basins. Several studies (e.g., Ding et al., 2011; Steig et al., 2013; Thomas et al., 2013; Meehl et al., 2016; Holland et al. 2019) have suggested the important tropical teleconnections that exist between the mid-latitudes/tropics and the West Antarctic. More specifically, positive anomalies in sea surface temperature in the tropical Pacific Ocean induce a convective heat event that further propagates to the West Antarctic region via the formation of Rossby wave train. 
Despite the large changes observed recently, the impact of the ASL variability on West Antarctic climate changes has not been fully studied because in-situ observations are lacking (Turner et al. 2004). Over the satellite era (from $1979 \mathrm{CE}$ ), atmospheric reanalyses seem to be reliable for studying the ASL variability and its impacts on the West Antarctic climate (Bracegirdle 2013). However, because of the high internal variability in the Amundsen region (e.g., Raphael et al., 2016), longer time-series are needed to understand the processes controlling the variability in the region.

In this study, we aim to better understand the West Antarctic climate variability on decadal to centennial timescales by analyzing the relationships between the main atmospheric variables with surface conditions and sea-ice cover. Furthermore, by making use of those potential links between variables, we provide historical estimations over the past two centuries that could not be directly observed. Special attention is given to the ASL, because of its major importance in the ongoing observed changes in West Antarctica. We investigate to which extent the ASL variability explains the West Antarctic climate change over the past two centuries, and if the role of the ASL has changed over time. The sea-ice extent (in particular the Bellingshausen/Amundsen Sea and Ross Sea sector) is also examined due to its key role in modulating West Antarctic climate (e.g., Lefebvre and Goosse, 2008; Thomas et al., 2013; Turner et al. 2017). Up to now, no spatial estimate of wind fields or sea-ice extent has been specifically validated for this region before the instrumental era and thus we aim to fill this gap. In addition to improving the general long-term changes in the West Antarctic climate, we assess the representativeness of the climate changes occurring during the second half of the $20^{\text {th }}$ century on a longer time perspective. Finally, a complementary goal is to highlight the mechanisms that explain the warming over West Antarctica as a whole and the strong regional asymmetry in sea-ice extent trends over the past decades.

To this end, we provide a spatially complete and multi-variate reconstruction of the West Antarctic climate changes over the past two centuries (the period for which most paleoclimate proxies are available; see below) by optimally combining paleoclimate records and a climate model using a data assimilation approach. Over last years, data assimilation has been increasingly applied in paleoclimatology for estimating past climate changes (e.g., Goosse et al., 2009 Hakim et al. 2016, Steiger et al., 2017, Goosse et al., 2010). Compared to simpler statistical methods (e.g., Stenni et al.| 2017; Emile-Geay et al., 2017), data assimilation does not assume a stationary relationship between the proxy and the climate. Data assimilation ensures that the resulting climate reconstruction is dynamically coherent. Such a method is also particularly relevant for regions like the West Antarctic where a strong coupling exists between the observed changes from various variables (Jones et al., 2016, Fan et al., 2014 Goosse et al., 2009). Here, the model is constrained by $\delta^{18} \mathrm{O}$ and snow accumulation records from Antarctic ice cores. Over the Antarctic, ice core is the most widespread climate archive for assessing historical climate changes at high temporal resolution (i.e., annual scale). Compared to the instrumental network, the ice core network is well developed over West Antarctica thanks 
to a number of international drilling efforts. In addition to the ice cores, we also make use of the tree-ring width records from the mid-latitudes that capture changes in past climate variability (e.g., Emile-Geay et al., 2017). The inclusion of non-specific-Antarctic proxies guarantees a large-scale coherence. This avoids forcing a local agreement with the Antarctic data that would not be based on processes compatible with larger-scale changes.

This study is organized as follows. Section 2 includes a description of the data assimilation method, the paleoclimate proxies and the model used for the reconstruction. We discuss the performance of our reconstruction in section 3 by comparing it with instrumental observations and other climate reconstructions, and discuss our main results, before concluding.

\section{Data assimilation method}

Data assimilation (DA) optimally combines the information from observations and the climate physics as included in climate models. In practice, the data assimilation process updates the initial state of the climate given by the model (i.e., the prior) according to the available observations to provide the best estimate of the climate state (i.e., the posterior), while also considering the errors associated with both the data and model. Paleo DA methods thus spread the local and temporal information from proxy records in space but also into other variables by relying on the modelled co-variance in space and among variables, respectively. For instance, the $500-\mathrm{hPa}$ geopotential height can be therefore reconstructed only by assimilating near-surface air temperature. In that situation, the reconstructed $500-\mathrm{hPa}$ geopotential height relies on the covariance relationships between the $500-\mathrm{hPa}$ geopotential height and nearsurface air temperature in the model. If there is no covariance between the variable of interest and the assimilated variable, the reconstruction skill of the variable of interest will be null. Consequently, the resulting multi-variate climate reconstruction guarantees a dynamical consistency in space and between variables, which is provided in a natural way with the climate model as it directly relies on the physics included in the climate model.

The DA method employed in this study is an offline approach (also called a no-cycling method). This method uses existing climate model simulations to draw the prior. In contrast to the standard online data assimilation approach, the prior is estimated by selecting different years of a climate model simulation. Therefore, no information is propagated in time. This approach is totally appropriate when the predictability time-scale of the system is much smaller than the data assimilation time step (here, one year). This is particularly true when assimilating atmospheric variables because of the small correlation time in the atmosphere. In such cases, no additional relevant information is gained when using an online approach, as shown by Matsikaris et al. (2015). 


\subsection{Particle filter}

The DA method used here is based on a particle filter following the implementation of Dubinkina et al. (2011). This method has been recently applied to reconstruct successfully large-scale near-surface air temperature and snow accumulation over Antarctica during the past millennia (Klein et al., 2019 Dalaiden et al. 2020a). We thus describe briefly the method here.

The particle filter (van Leeuwen, 2009) aims at updating an initial estimate of the state of the system, referred to as the prior, using additional information provided by available observations, following the classical approach of Bayesian reconstructions. Specifically, the prior for each variable is represented by a probability density function (pdf), described in a discrete way using a set of independent model states, which are called particles. These model states are given by all the years (annual mean) of an ensemble of three simulations performed with the isotope-enabled Community Earth System Model version 1 (iCESM1; Brady et al., 2019, Stevenson et al., 2019) spanning the 850-1850 CE period (see section 2.5 for the model evaluation). The prior thus includes 3003 particles and is constant throughout the data assimilation process. At each assimilation step (here every year), the particles forming the prior are evaluated against the available observations while taking into account the error associated with the observations as well as the inconsistency between the observations and model related to unresolved processes in the model (i.e., the observation error; see section 2.6. As a result of this comparison with observations, each particle of the prior receives a weight that is proportional to its likelihood knowing the observations. The weights are thus higher for the particles closer to the observations than for the particles further to the observations. In other words, the particle filter redistributes the weights of all the particles at each time step to obtain posterior distribution in better agreement with observations. Since only the weights of the particles can change during the data assimilation process, the climate dynamics as represented in the model is fully respected. For each time step, the climate reconstruction is defined as the weighted mean of all the particles. We define the reconstruction uncertainty as the weighted standard deviation of all the particles. For more details on the implementation of the particle filter, see Dubinkina et al. (2011).

\subsection{Evaluation metrics}

In order to quantify the performance of our reconstruction, we use three different metrics that compare the results with observations or other reconstructions. The first one is the Pearson correlation coefficient $(r)$, which determines the strength of the linear relationship between two time-series:

$$
r=\frac{1}{n} \sum_{i=1}^{n}\left(\frac{\left(y_{i}-\bar{y}\right)\left(x_{i}-\bar{x}\right)}{\sigma_{y} \sigma_{x}}\right)
$$


where $n$ is the number of samples, $y$ stands for the predicted vector while $x$ is the true vector. Overbars indicate the mean over the time. $\sigma_{y}$ and $\sigma_{x}$ are the standard deviations of $y$ and $x$, respectively. Although a high value of $r$ indicates that the predicted values follow the direction of the true values, it does not ensure that the variations of the amplitude are well reproduced. Therefore, the second metric is the coefficient of efficiency (Nash and Sutcliffe 1970), which depends on the amplitude of the signal:

$$
\mathrm{CE}=1-\sum_{i=1}^{n} \frac{\left(x_{i}-y_{i}\right)^{2}}{\left(x_{i}-\bar{x}\right)^{2}}
$$

A high value for $\mathrm{CE}$ thus indicates that both the timing and the amplitude are right. Finally, we need to verify if the ensemble reconstruction is similar to the reconstruction error relative to observations. For this purpose, we compute the ensemble calibration ratio (ECR) defined here as:

$$
\mathrm{ECR}=\operatorname{median}\left[\frac{\left(x_{i}-y_{i}\right)^{2}}{\sigma_{x, i}^{2}}\right]
$$

where $i$ varies from 0 to $n$ and $\sigma_{x, i}^{2}$ is the variance of the reconstruction ensemble. An ECR of 1 means that the reconstruction is well calibrated (i.e., the reconstruction error equals the uncertainty of the reconstruction). When ECR $<1$, the estimation of the uncertainty of the reconstruction is too large compared to the error over the analyzed period. On the contrary, when $\mathrm{ECR}>1$, the estimate of the uncertainty is likely too low compared to the real reconstruction error.

\subsection{Proxy data}

From the 79 ice core snow accumulation records included in the database of Thomas et al. (2017), we only keep the annually-resolved records (48 out of 79) as in Medley and Thomas (2019). Medley and Thomas (2019) provide a spatially complete annual Antarctic snow accumulation over the past two centuries using this ice core snow accumulation database (Fig. 1). This excludes a majority of snow accumulation records in the continental Dronning Maud Land region. As in Medley and Thomas (2019), we also add the B40 ice core record of snow accumulation (Medley et al. |2018), which was published after the compilation of Thomas et al. (2017). Additionally, we also employ the information from the ratio of stable isotopes oxygen in the ice core $\left(\delta^{18} \mathrm{O}\right)$. Stenni et al. (2017) provide a compilation of the Antarctic precipitation-weighted $\delta^{18} \mathrm{O}$ records $(n=112)$ covering the last two millennia. We only keep the 29 annually-resolved $\delta^{18} \mathrm{O}$ records. It is worth noting that the majority of the ice cores (both snow accumulation and $\delta^{18} \mathrm{O}$ records) are located in West Antarctica (WAIS; Fig. 1).

In addition to the Antarctic proxies, we also utilize the continental annuallyresolved proxies situated in the Southern Hemisphere from the global database 

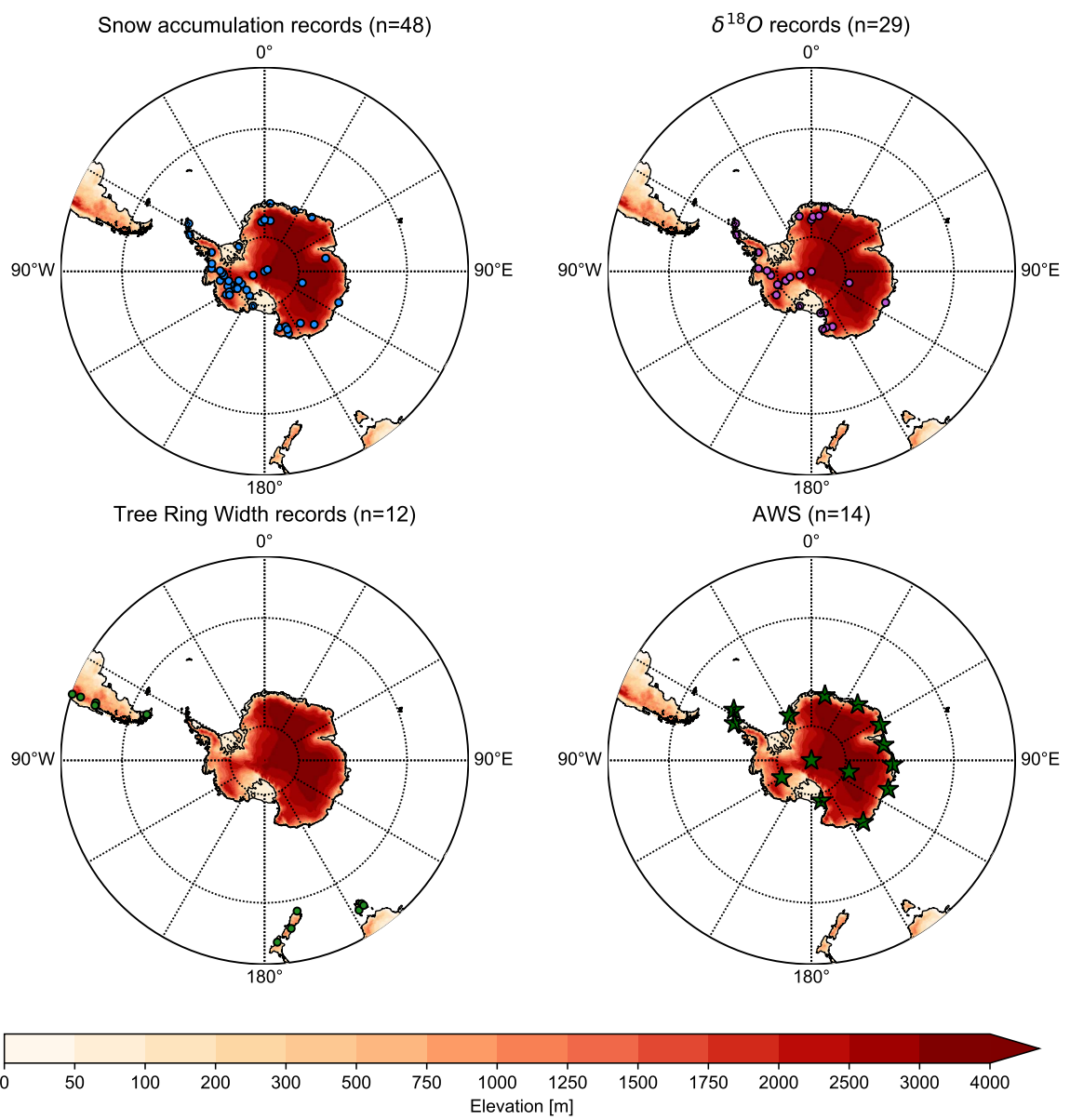

Fig. 1 Annually-resolved climate/proxy records used in this study: snow accumulation records (blue dots), $\delta^{18} \mathrm{O}$ records (purple squares), Automatic Weather Stations (AWSs; green stars) and tree-ring width records (green dots). The map background represents the surface elevation $(\mathrm{m})$.

of the PAGES2k working group that includes all the proxy records suitable for reconstructing the global temperature over the last two millennia (PAGES2k Consortium et al., 2013; Emile-Geay et al., 2017). Among all the continental proxies included in the global database for the Southern Hemisphere, only the tree-ring width (hereafter TRW) are annually-resolved (in addition to some Antarctic ice cores already included in our study). A total of 18 sites presenting TRW time-series over past centuries are located in the Southern Hemisphere : three in New Zealand, three in Tasmania and 12 in South America. Among the 12 South American sites, only six are positively correlated with climate (either near-surface air temperature or precipitation) according to our 
dataset (see section 2.4) over the 1941-1990 CE period, and thus included. The geographical distribution of the selected sites is presented in Fig. 1.

Most proxy records cover the last two centuries, but their number starts to decline from around $1990 \mathrm{CE}$ (Fig. S1). Therefore, the period analyzed throughout the study is 1800-2000 CE. This provides a good compromise in terms of the number of records and the overlap with the satellite period (starting in $1979 \mathrm{CE}$ ) that is used for the evaluation of the reconstruction (see section 3.1). This period was also used in the study of Medley and Thomas (2019) who reconstructed snow accumulation in Antarctica using the same ice core snow accumulation records as here.

In order to reduce the non-climatic noise and provide equal weighting in each region (i.e not bias a particular region with multiple records), a 500 $\mathrm{km}$ grid (square cells of $500 \mathrm{~km}$ side) was established and records from the same grid were averaged together. For snow accumulation records, they are all normalized over the 1941-1990 CE period (mean zero and unit standard deviation) and the records situated in the same cell are averaged. The mean of normalized snow accumulation records for each grid cell produces the normalized composites. For each composite, the variance is then scaled to the variance of the spatial snow accumulation reconstruction from Medley and Thomas (2019), linearly interpolated on the $500 \mathrm{~km}$ grid over the 1941-1990 CE period. Compared to snow accumulation, the $\delta^{18} \mathrm{O}$ records display a weaker spatial variability as they are less dependent on the topography and do not need normalization. Instead, $\delta^{18} \mathrm{O}$ composites for each grid cell are obtained by averaging the anomalies of $\delta^{18} \mathrm{O}$ records over the 1941-1990 CE. Finally, we apply the same methodology as for the snow accumulation records to TRW time-series, but without correcting the variance (z-scored composites) since TRW data is originally normalized.

\subsection{Proxy System Models}

Snow accumulation records are directly compared to the precipitation minus sublimation/evaporation $(P-E)$ from the climate model simulation. Snow accumulation recorded in ice cores is the sum of both precipitation and post depositional changes (wind erosion, sublimation and melt). Several studies have shown that precipitation dominates and that snow accumulation can be directly compared with the precipitation minus sublimation/evaporation $(P-E)$ from the climate model simulation (Lenaerts et al., 2017; Souverijns et al., 2018, van Wessem et al., 2018, Agosta et al., 2019). This is particularly true when working at a large spatial scale - as in our study (500 km grid) - and over the grounded ice sheet (i.e., the Antarctic Ice Sheet without ice shelves) (Agosta et al. 2019). Additionally, since iCESM1 explicitly simulates the ratios of water isotopes in all the climate components, the $\delta^{18} \mathrm{O}$ records are also directly compared to the $\delta^{18} \mathrm{O}$ simulated by the model.

A Proxy System Model (PSM) specifically designed for the TRW is required in order to compare the model results to the proxy. To this end, a TRW 
PSM is built for each TRW time-series. Instead of a mechanistic model, which simulates tree-ring growth by explicitly including the biological processes that drives the relationship between climate and tree growth (e.g., Guiot et al. 2014, Misson, 2004, Dufrêne et al., 2005, Rezsöhazy et al., 2020), we use a simple statistical model. It has the advantage of being easily implemented but the relationship between climate and tree growth is estimated empirically, without taking into account any biological processes. This method is similar to the one used in the Last Millennium Reanalysis (Tardif et al., 2019).

In this study, we consider that trees are sensitive to the temperature or precipitation, or to both. Therefore, we introduce two types of models:

$$
\begin{gathered}
y_{i}=\beta_{0 i}+\beta_{1 i} X_{1 i}+\epsilon_{i} \\
y_{i}=\beta_{0 i}+\beta_{1 i} X_{1 i}+\beta_{2 i} X_{2 i}+\epsilon_{i}
\end{gathered}
$$

where $y_{i}$ corresponds to the observed z-scored TRW time-series (i.e., the dependent variable) for site $i ; \beta_{1 i}$ and $\beta_{2 i}$ are the slopes associated with the $X_{1 i}$ and $X_{2 i}$ of the $i$ time-series, which are the explanatory variables; $\epsilon_{i}$ are the errors, assumed to be normally (Gaussian) distributed with a zero mean and a unitary variance $\left(0, \sigma^{2}\right)$. Parameters of the Eqs. (4) and (5) are estimated using the ordinary least squares method.

Similarly to the Last Millennium Reanalysis (Tardif et al. 2019), we use the near-surface air temperature and precipitation as explanatory variables $\left(X_{1}\right.$ and $\left.X_{2}\right)$. In addition to the annual mean of near-surface air temperature and precipitation, the climate variables are also averaged over different months during the calendar year (January to December), in order to take into account the seasonal response of trees: JJA and OND. All the possible combinations are tested. The calibration of the PSM is performed over the 1941-1990 CE period using the Global Meteorological Forcing Dataset for land surface modeling (v2; http://hydrology.princeton.edu/data.php, last access: 22 June 2020; hereafter GMF) (Sheffield et al., 2006) interpolated on the $500 \mathrm{~km}$ grid excluding the oceanic grid cells. The sensitivity to the climate data has been assessed by also performing the calibration with the surface temperature from the NASA Goddard Institute for Space Studies Surface Temperature Analysis (Hansen et al. 2010) and precipitation from the Global Precipitation Climatology Centre (Schneider et al. 2014). Results display no major difference (not shown).

To select the best PSM for each TRW composite, we rely on the Bayesian information criterion (BIC) (Schwarz, 1978) value defined as :

$$
\mathrm{BIC}=-2 * L L+\log (n) * k
$$

where $L L$ is the natural logarithm of the likelihood for the model - estimated as the mean squared error of the linear regression model (Watkins and Mardia, 1992) - and $k$ corresponds to the number of parameters in the regression model (i.e., 2 and 3 for the uni and bi-variate models, respectively). The BIC 
is a particularly relevant metric to select the best model among uni and bivariate models as the most complex models are penalized. Accordingly, the PSM displaying the lowest BIC is selected.

\subsection{Climate model simulation}

The initial estimate of the state of the climate system (i.e., the prior) is derived from an ensemble of three simulations performed with the isotope-enabled iCESM1 spanning the 850-1850 CE time period (Brady et al., 2019, Stevenson et al. 2019). iCESM1 is a coupled atmosphere-ocean model including a sea-ice component. The atmosphere is resolved at approximately $2^{\circ}$ and the ocean at $1^{\circ}$. The iCESM1 simulations include the orbital changes, the solar variability, the volcanic forcing through changes in stratospheric aerosols and greenhouse gases, the land use changes and finally the human-induced greenhouse gases (Stevenson et al., 2019).

Although numerous studies have shown that CESM is well-suitable for studying the Antarctic climate over the past, present and future (Lenaerts et al., 2016; Fyke et al., 2017; England et al., 2016; Lenaerts et al., 2018; Dalaiden et al., 2020b), this version has not yet been evaluated over the Antarctic continent. As the information from proxy records is spread spatially and into other variables using the climate model, it is important to assess the performance of the model used in the data assimilation in simulating the near-surface climate over the Antarctic. Therefore, we briefly evaluate the Antarctic climate as simulated by iCESM1 by comparing it to the latest ECMWF's atmospheric reanalysis, ERA5 (Hersbach et al. 2020). It is considered as one of the best reanalyses in simulating the Antarctic climate over the satellite-era (Gossart et al., 2019, Tetzner et al., 2019). Since the paleoclimate proxies used in this study are annually-resolved, the evaluation is carried out on annual averages.

Over the 1979-2005 CE period, the geopotential height at $500-\mathrm{hPa}$ is well simulated in iCESM1 (Fig. S2; below south of $45^{\circ} \mathrm{S}, \mathrm{R}^{2}=97 \%$; relative bias $=-0.2 \%$ computed as the mean relative difference between the $500-\mathrm{hPa}$ geopotential height from iCESM1 and ERA5 south of $45^{\circ} \mathrm{S}$ ) and includes the three main low-pressure systems in Amundsen Sea, Dronning Maud Land and Wilkes Land. Regarding the near-surface air temperature, iCESM1 simulates the temperature gradient with the highest temperatures along the coasts and the lowest temperatures in the interior of the ice sheet (over the Antarctic continent, $\mathrm{R}^{2}=76 \%$; relative bias $=-2.0 \%$ ). Like temperature, snow accumulation is highly dependent on the topography. iCESM1 reproduces the Antarctic snow accumulation pattern well from ERA5 $\left(\mathrm{R}^{2}=85 \%\right.$ - based on log values as the snow accumulation distribution is log-normal (Agosta et al. 2019); relative bias=-6.9\%). However, iCESM1 is not able to reproduce the high spatial variability of snow accumulation at local scale, because of its coarse horizontal spatial resolution. Besides, iCESM1 displays a total Antarctic seaice extent of $11.710^{6} \mathrm{~km}^{2}$ against $11.910^{6} \mathrm{~km}^{2}$ for observations from the 
National Snow and Ice Data Center (NSIDC; data available here: https: //nsidc.org/data/NSIDC-0051/versions/1, last access: 5 September 2018). Compared with the NSIDC observations, iCESM1 overestimates by $5 \%$ the mean sea-ice extent in the West Antarctic sector $\left(160^{\circ} \mathrm{W}-60^{\circ} \mathrm{E}\right)$ over $1979-2005$ $\mathrm{CE}$, with a similar bias in both the Bellingshausen/Amundsen Sea $\left(130^{\circ} \mathrm{W}\right.$ $\left.60^{\circ} \mathrm{E}\right)$ and Ross Sea $\left(160^{\circ} \mathrm{E}-130^{\circ} \mathrm{W}\right)$ sectors $(5.4 \%$ and $4.8 \%$, respectively; Tab. $\mathrm{S} 1)$. This suggests that iCESM1 is able to simulate relatively well the mean state of Antarctic sea-ice extent at present. Finally, although a quantitative evaluation of the simulated precipitation-weighted $\delta^{18} \mathrm{O}$ is not possible because of the insufficient amount of Antarctic observations (three records in the Global Network of Isotopes in Precipitation), the precipitation-weighted $\delta^{18} \mathrm{O}$ pattern over Antarctica captures the gradient between the coasts (with the highest values, less negative) and the Plateau (with the lowest values, more negative) due to isotopic fractionations (Fig. S3). Based on the skill of iCESM1 in simulating present-day Antarctic climate, we deem this model suitable for building the prior of the data assimilation experiment. As proxy data are averaged over a $500 \mathrm{~km}$ regular grid (see section 2.3), the prior has also been linearly interpolated onto this $500 \mathrm{~km}$ regular grid.

\subsection{Observation error}

Data assimilation requires an error of the assimilated data. This observation error plays a crucial role in data assimilation because it determines the extent to which each assimilated record is influencing the reconstruction. The records with a low observation error will thus have a larger weight in the data assimilation than the records with a high observation error.

Three types of observation errors are usually mentioned (e.g., Badgeley et al. 2020). The first type of observation error directly comes from the accuracy of the measurement, i.e., the instrumental error. The second type of observation error is related to the processes in observations that are unresolved at the spatial scale of the model because of its coarse resolution, the so-called representativeness observation error (e.g., Oke and Sakov, 2008, Janjić et al. 2018). Finally, the last type of observation error arises from the performance of the PSM in simulating the relationship between the proxy and the climate variable(s). Overall, the instrumental error is much smaller than the two other observation errors (e.g., Oke and Sakov, 2008), especially in paleoclimatology (Tardif et al. 2019: Steiger et al. 2018: Badgeley et al., 2020). This observation error is thus ignored in our study. Finally, regarding the snow accumulation and $\delta^{18} \mathrm{O}$ records, we assume that the observation error related to the PSM is non-existent, since the model simulates both variables. The representativeness error is thus considered as the largest contributor to the observation error. Therefore, for ice core snow accumulation and $\delta^{18} \mathrm{O}$ records, the observation error is taken equal to the representativeness error. However, for tree-ring width records, the observation error combines the representativeness error and the PSM-related observation error as the climate model used in the data assimi- 
lation does not simulate tree growth. In contrast, the climate model simulates the snow accumulation and $\delta^{18} \mathrm{O}$. As a consequence, a PSM simulating those variables is not required.

To estimate the representativeness error of the snow accumulation composite associated with the ice core records, we use an Antarctic simulation performed with the latest version of the Regional Atmospheric Climate MOdel (RACMO2.3p2, hereafter RACMO) at $27 \mathrm{~km}$ horizontal resolution (van Wessen et al. 2018). RACMO is a polar-oriented regional climate model that specifically resolves near-surface processes over Antarctica. For each snow accumulation composite, we proceed as follows. We retrieve the annual time-series of snow accumulation from RACMO at the location of all the ice core snow accumulation records included in the composite over the 1979-2016 CE period (period over which RACMO results are available). In order to remove the dependence on the elevation, the calculation is performed on time-series anomalies. All RACMO-time series are then averaged in time. Next, we compute the difference between this averaged snow accumulation time-series and the snow accumulation time-series from RACMO interpolated on the $500 \mathrm{~km}$ grid (i.e., the resolution of snow accumulation composites; see section 2.3. Eventually, the representativeness error is defined as the standard deviation of the time-series difference. Note that the representativeness error is calculated for each year of the composite (1800-2000 CE), based on the snow accumulation RACMO data (1979-2016 CE). As the number of ice cores in the composite decreases when going further back in time, the representativeness error tends to increase. Finally, since RACMO does not simulate the $\delta^{18} \mathrm{O}$, we use the iCESM1 linearly interpolated on the RACMO grid over the 1950 $2005 \mathrm{CE}$ period to estimate the $\delta^{18} \mathrm{O}$ representativeness error with the same methodology. A 50-year period minimizes the potential biases induced by the variability of the $\delta^{18} \mathrm{O}$ when using a too short time period and thus ensures the computation of a robust estimate. We have selected the final part of the series to have the largest overlap with the period over which the snow accumulation error is computed. This in part guarantees consistency in the calculation of the representativeness error for the snow accumulation and $\delta^{18} \mathrm{O}$ records.

However, several studies (van Wessem et al., 2018, Lenaerts et al., 2016 Cavitte et al. 2020 have shown that the spatial variability of snow accumulation and $\delta^{18} \mathrm{O}$ is underestimated in models (i.e., RACMO and iCESM1) compared to ice core observations. Therefore, using these models to estimate the observation error in our study probably also underestimates the observation errors. In order to provide an observation error closer to the reality, we take into account the missing processes occurring between the scale represented in the models and the local scale of ice cores. This is achieved by performing a side-by-side comparison between adjacent snow accumulation records as in Fisher et al. (1985). More specifically, we compute the standard deviation of the difference between each pair of annual time-series of snow accumulation records (in anomalies) within the same grid cell of the $500 \mathrm{~km}$ grid over the 1941-1990 CE (which is the most recent 50-year period for which all the ice core records are available; Fig. S1). The calculation is made for all the possible 
combinations within the grid cell. According to the grid cell containing more than five ice cores ( $n=2$; both situated in West Antarctica), the side-by-side comparison suggests that the error at the ice core-scale is higher by a threefactor compared to the one at the scale of RACMO. The same exercise for $\delta^{18} \mathrm{O}$ has been carried out and shows similar results (not shown).

Regarding the TRW composites, the error is estimated by taking the standard deviation of the residuals resulting from the linear regression (see Eqs. (4) and (5)) as in the Last Millennium Reanalysis (LMR) (Hakim et al., 2016, Tardif et al. 2019). The error thus encompasses the representativeness error and the error related to the PSM since the PSM has been calibrated using the climate data interpolated on the $500 \mathrm{~km}$ grid and not using the local data. After performing several sensitivity tests, we have found that our results present a small sensitivity to reasonable modification of the estimation of the observation error (not shown).

\subsection{Instrumental data assimilation-based reconstruction}

Before using the paleo records to reconstruct the Antarctic climate over the past centuries (hereafter referred to as the paleo-reconstruction), we first reconstruct the Antarctic climate over the 1958-2000 CE period using data assimilation with near-surface air temperature records and snow accumulation records from ice cores. Applying a methodology that is as close as possible to the one selected for the longer timescales allows us to validate the approach, in particular the data assimilation method and the estimations of the errors using observations with lower uncertainties than the paleo records. This reconstruction based on instrumental and snow accumulation records thus provides an upper bound for the skill we could expect with the paleoclimate network. To this end, we assimilate the near-surface air temperatures from the Automatic Weather Stations (AWSs) over the Antarctic continent (Turner et al. 2004) $(n=14)$ starting from $1958 \mathrm{CE}$ (see Fig. 1 for their geographical localization). The model is also constrained by the snow accumulation records from ice cores, which are the best estimate of long-term snow accumulation, since AWSs do not record this variable. Additionally, TRW records are replaced by the near-surface air temperatures from the gridded dataset used for the calibration of the TRW PSM (i.e., GMF; only where TRW sites are available). This reconstruction is referred to as the instrumental reconstruction.

The observation error on the near-surface air temperature from AWSs is calculated similarly to the snow accumulation error (see section 2.6) but using near-surface air temperatures from RACMO. Like for the snow accumulation and $\delta^{18} \mathrm{O}$ records, we assume that the observation error for the Antarctic near-surface air temperature is mainly due to the representativeness error. This error should take into account the missing processes occurring between the local scale (i.e., the AWS scale) and the scale of RACMO (i.e., 27-km resolution). Nevertheless, the network of AWS starting from $1958 \mathrm{CE}$ is much less dense than the paleo records (Fig. 1). Therefore, a side-by-side comparison 
of adjacent near-surface air temperature time-series as we did for paleo records is not possible (see section 2.6. We are thus not able to provide an accurate estimate of the factor to make the link between local observation error and the error at the scale on the climate model grid. However, several studies (e.g., Agosta et al., 2019, van Wessem et al., 2018) showed a weaker spatial variability of near-surface air temperature compared to snow accumulation (e.g., Agosta et al., 2019, van Wessem et al., 2018). Therefore, we assume that the factor applied to take into account the unresolved processes at the RACMO scale is smaller than for snow accumulation (see section 2.6) and multiply the local observation error of near-surface air temperature for the Antarctic AWSs by a two-factor. Finally, the situation is very different for the assimilated nearsurface air temperature of the gridded dataset GMF associated with the TRW sites as it is a gridded dataset at a resolution similar to the one of the model that is thus expected to represent processes at a similar scale. Therefore, a constant error of $0.5^{\circ} \mathrm{C}$ is chosen, which is a typical value when assimilating gridded near-surface air temperature (e.g., Brennan et al., 2020; Dubinkina et al. 2011).

\section{Results and discussion}

3.1 Validation of the instrumental paleo reconstructions over the last decades

Before analyzing the long-term changes using the paleo-reconstruction over the past centuries, we first need to ensure that our data assimilation method works. We establish this by testing the skill of the instrumental and paleo reconstructions at reproducing interannual climate variability and trends over the last decades, in particular the atmospheric circulation, near-surface continental climate (temperature and snow accumulation) and sea-ice cover. To this end, Figure 2 presents the spatial correlation coefficients between our instrumental and paleo reconstructions and the latest ECMWF atmospheric reanalysis ERA5 (Hersbach et al. 2020) over the 1979-2000 CE period for the 500-hPa geopotential height, near-surface air temperature and snow accumulation, as well as sea-ice concentration using the dataset from the National Snow and Ice Data Center (NSIDC) (Parkinson, 2019). Although the period is short (22 years), this evaluation gives a first indication of the performance of our reconstruction when compared to independent data.

\subsubsection{Near-surface air temperature}

For continental near-surface air temperature, our spatial instrumental reconstruction is highly correlated with ERA5 over West Antarctica (Fig. 2). Our instrumental reconstruction is also close to the reconstruction of Nicolas and Bromwich (2014) - which is based on the same near-surface air temperature observations as in our reconstruction but using a kriging interpolation over 
1958-2000 CE -, when averaging over the two main regions of the West Antarctic continent, i.e., the West Antarctic Ice Sheet (WAIS; $60-180^{\circ} \mathrm{E}$ and south of $72^{\circ} \mathrm{S} ; r=0.88$ (p-value $\left.\left.<0.05\right), \mathrm{CE}=0.71, \mathrm{ECR}=0.27\right)$ and the Antarctic Peninsula (AP; west longitude north of $72^{\circ} \mathrm{S} ; r=0.78$ (p-value $<0.05$ ), $\mathrm{CE}=0.56$, $\mathrm{ECR}=0.60$; Fig. $3 \mathrm{a}, \mathrm{b})$. The high $\mathrm{CE}$ and $r$ values mean that both the interannual variability and the amplitude of changes are similar between the two reconstructions. ECR values are largely less than one, which suggests that our reconstruction ensemble has too much variance compared to the mean squared error. However, this result is not surprising since both our instrumental reconstruction and Nicolas and Bromwich (2014) used the same near-surface air temperature dataset for the assimilation. Although the skill metrics are lower for the AP compared to the WAIS, our reconstruction correctly displays the largest warming in AP $\left(0.38^{\circ} \mathrm{C}\right.$ per decade $)$ as in Nicolas and Bromwich (2014) $\left(0.46{ }^{\circ} \mathrm{C}\right.$ per decade).

Comparing our paleo-reconstruction to the instrumental reconstruction shows that using paleo records instead of actual observations degrades the skill of the overall reconstruction, which is expected (Figs. 2 and $3 \mathrm{a}, \mathrm{b}$ ). However, near-surface air temperatures in the paleo-reconstruction still remain highly correlated with ERA5. This is in line with the good agreement with the nearsurface air temperature reconstruction from Nicolas and Bromwich (2014) for the AP $(r=0.62(\mathrm{p}$-value $<0.05), \mathrm{CE}=0.21, \mathrm{ECR}=0.95)$ and WAIS $(r=0.53(\mathrm{p}-$ value $<0.05), \mathrm{CE}=0.28, \mathrm{ECR}=0.37)$. For the linear trends over the 1958-2000 $\mathrm{CE}$ period, similarly to Nicolas and Bromwich (2014), our paleo-reconstruction displays warming of $0.42{ }^{\circ} \mathrm{C}$ per decade and $0.15{ }^{\circ} \mathrm{C}$ per decade for $\mathrm{AP}$ and WAIS respectively, which is closer than for our instrumental reconstruction (Fig. 3a,b). Our paleo-reconstruction therefore captures the trend better than the instrumental reconstruction, which could be related to the denser paleo network, but not the spatial variability, nor the interannual variability.

\subsubsection{Snow accumulation}

The snow accumulation from our instrumental reconstruction is less correlated with ERA5 than the near-surface air temperature, and displays a reduced area with statistically significant correlation coefficients (Fig. 2). This could be partially explained by the much higher spatial variability of snow accumulation over the Antarctic continent, compared to near-surface air temperature van Wessem et al., 2018, Agosta et al., 2019). Additionally, as all atmospheric reanalyses, ERA5 suffers from larger biases in snow accumulation than in near-surface air temperature (Gossart et al. 2019). At first order, the spatial variability of both near-surface air temperature and snow accumulation follows the topography (high temperature and snow accumulation on coastal areas, slowly decreasing towards the interior of the ice sheet), but snow accumulation is more affected by local processes, for example related to the wind (snow erosion/deposition and blowing snow) (Agosta et al. 2019). As a consequence, some snow accumulation records may be poorly correlated with snow accumulation derived from atmospheric reanalyses (Medley and Thomas, 2019). This 


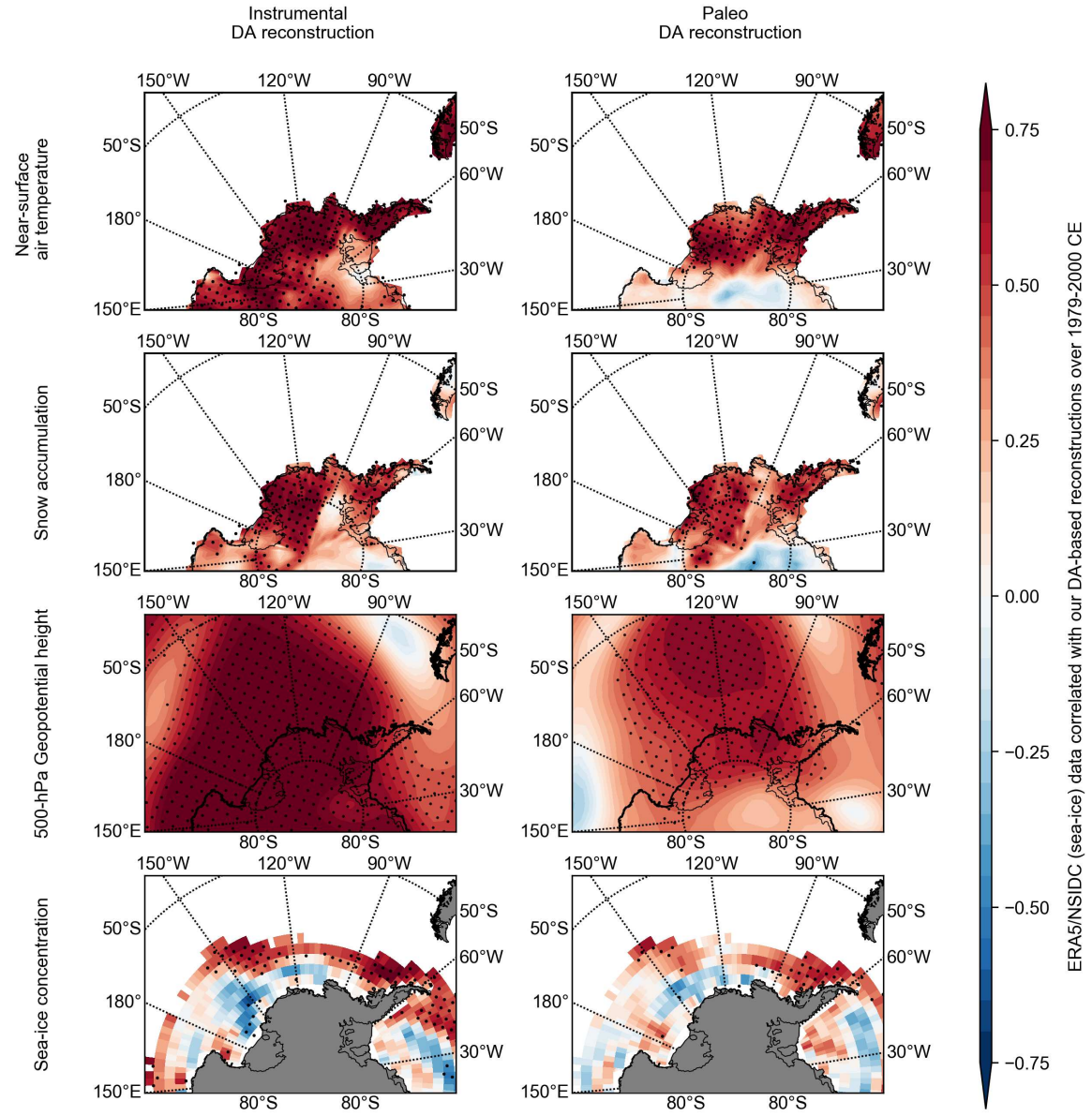

Fig. 2 Spatial correlation coefficients $(r)$ between our instrumental (left) and paleo (right) reconstructions and the ERA5 reanalysis for the near-surface air temperature, snow accumulation, 500-hPa geopotential height and the sea-ice concentration from the National Snow and Ice Data Center (NSIDC) over the 1979-2000 CE period. Stippling indicates statistically significant correlations (95\% confidence level).

is particularly prevalent for regions in East Antarctica (Medley and Thomas, 2019). Since these snow accumulation records are used in our data assimilation, it is not surprising to obtain lower correlation coefficients for those areas.

When evaluating our snow accumulation reconstruction compared to the snow accumulation reconstruction from Medley and Thomas (2019), the skill metrics show that our instrumental reconstruction displays good and similar performance for the WAIS $(r=0.64(\mathrm{p}$-value $<=0.05), \mathrm{CE}=0.40$ and $\mathrm{ECR}=0.21)$ and $\operatorname{AP}(r=0.54$ (p-value $<=0.05), \mathrm{CE}=0.24$ and $\mathrm{ECR}=2.37$; Fig. 3 $\mathrm{k}, \mathrm{d})$. Moreover, both our instrumental reconstruction and the reconstruction of Medley and Thomas (2019) show a positive linear trend in West Antarctic-wide snow 

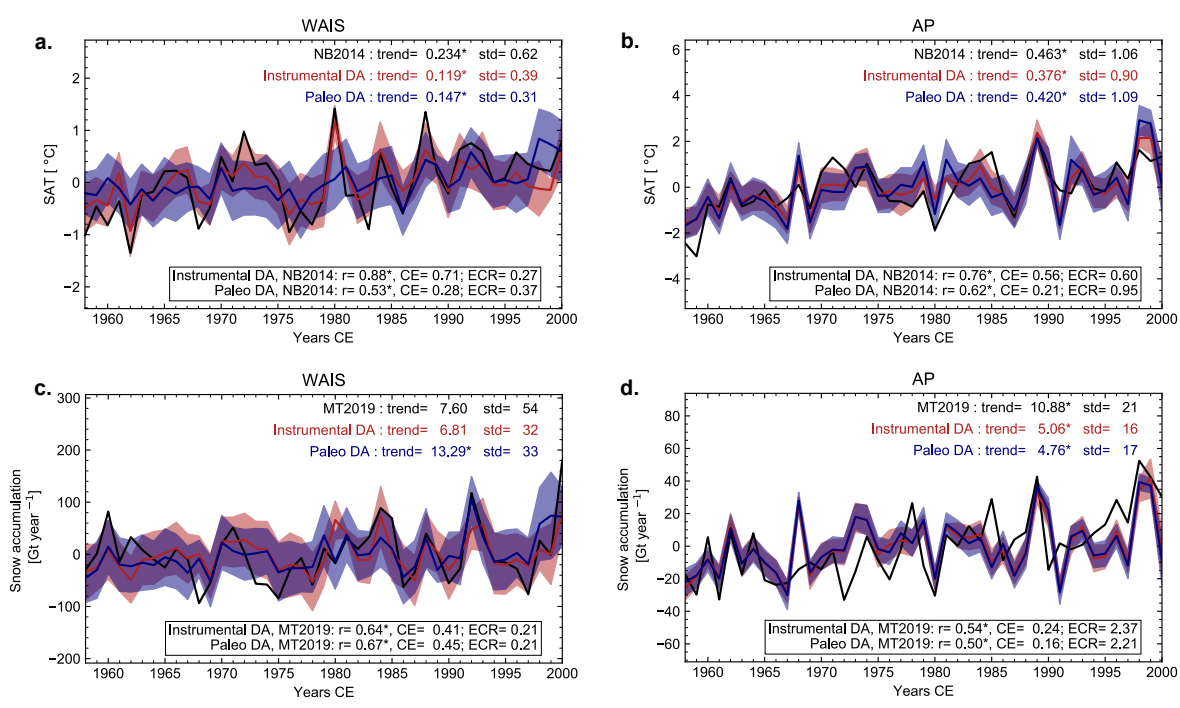

Fig. 3 (a-b) Comparison between our instrumental (red) and paleo (blue) near-surface air temperature $\left(\mathrm{SAT} ;{ }^{\circ} \mathrm{C}\right.$ ) anomalies and the reconstruction of Nicolas and Bromwich (2014 NB2014; in black) for the West Antarctic Ice Sheet (WAIS; $60-180^{\circ} \mathrm{E}$ and south of $72^{\circ} \mathrm{S}$ ) and the Antarctic Peninsula (AP; west longitude north of $72^{\circ} \mathrm{S}$ ) and over the 1958-2000 CE period. Regional definitions are identical as in Steig et al. (2009). (c-d) Comparison between our instrumental (red) and paleo (blue) snow accumulation (Gt year ${ }^{-1}$; in red) anomalies and the reconstruction of Medley and Thomas (2019, MT2019; in black) for the West Antarctic Ice Sheet (WAIS) and the Antarctic Peninsula (AP) and over the 19582000 CE period. Anomalies are computed over the 1958-2000 CE period. Linear trends of near-surface air temperature trends and snow accumulation are displayed (expressed in ${ }^{\circ} \mathrm{C}$ decade ${ }^{-1}$ and Gt year ${ }^{-1}$ decade ${ }^{-1}$, respectively) and the standard deviation (std) of the time-series (expressed in ${ }^{\circ} \mathrm{C}$ and $\mathrm{Gt}$ year ${ }^{-1}$, respectively) over the $1958-2000 \mathrm{CE}$ period for each region. Asterisks indicate statistically significant trends at the $95 \%$ confidence level. Additionally, the correlation coefficient $(r)$, coefficient of efficiency $(\mathrm{CE})$ and ensemble calibration ratio (ECR) are computed over the 1958-2000 CE period. Error bands correspond to the reconstruction uncertainty as defined in section 2.1

accumulation (i.e., the sum of the WAIS and AP regions) over the 1958-2000 CE period: $18.48 \mathrm{Gt}_{\text {year }}{ }^{-1}$ per decade and $11.46 \mathrm{Gt} \mathrm{year}^{-1}$ per decade, respectively (both statistically significant; p-value $<0.05$ ). However, it is worth noting that our instrumental reconstruction for the AP displays a smaller linear trend than in the reconstruction of Medley and Thomas (2019) (5.06 Gt year $^{-1}$ per decade against $16.88 \mathrm{Gt}_{\text {year }}{ }^{-1}$ per decade, respectively). Additionally, the ECR for the AP reaches 2.37, which means that the uncertainty in our reconstruction is underestimated.

Finally, the performance of our paleo-reconstruction for snow accumulation is close to the instrumental reconstruction (Fig. 3k,d). The degradation of the performance between the instrumental and paleo reconstructions is very limited for snow accumulation compared to near-surface air temperature, which is expected as we use the same observational dataset in the two reconstructions of snow accumulation. Moreover, our paleo-reconstruction displays a $18.04 \mathrm{Gt}$ 
year $^{-1}$ per decade linear trend for the West Antarctic-wide snow accumulation over 1958-2000 CE, which is very close to Medley and Thomas (2019) (18.48 Gt year ${ }^{-1}$ per decade over the same period).

\subsubsection{Atmospheric circulation}

Unlike near-surface air temperature and snow accumulation, no pressure data is used in the data assimilation process for both the instrumental and paleo reconstructions. The skill of the reconstruction of the non-assimilated variables is thus expected to be lower than for the assimilated variables. Spatial correlation coefficients between our instrumental reconstruction and the ERA5 reanalysis for the 500-hPa geopotential height during the 1979-2000 CE period show that interannual changes in the atmospheric circulation are well reconstructed over the West Antarctic and in the mid-high latitudes of the Pacific Sector of the Southern Hemisphere (Fig. 21). Furthermore, for the paleo-reconstruction, the stronger correlations over the ocean, compared to the continent, reflect the fact that changes in this region are driving the variability recorded in ice cores. This confirms that marine intrusions predominantly govern the nearsurface climate variability in West Antarctica (Nicolas and Bromwich, 2011). This also gives confidence in the use of ice core records for reconstructing the atmospheric circulation in that sector.

We also analyze the Amundsen Sea Low pressure (ASL), which can be characterized by several indexes (e.g., Hosking et al., 2013), for example related to the change in the ASL position (latitudinal and longitudinal positions) or to the intensity of the minimum pressure in the ASL region. Here, the ASL index is defined as the annual average of the $500-\mathrm{hPa}$ geopotential height from $75^{\circ} \mathrm{S}$ to $60^{\circ} \mathrm{S}$ and from $170^{\circ} \mathrm{E}$ to $70^{\circ} \mathrm{W}$ (Fogt et al. 2012; Turner et al., 2013, Hosking et al., 2013). Note that geographical definitions can differ between studies but the resulting indexes are relatively similar. This index is then normalized (zero mean and unity standard deviation) over the 1941-1990 CE period. Following this definition, a negative (positive) ASL index corresponds to a deeper/stronger (weaker) ASL. Because no reconstruction of the ASL index exists, we use the ASL index derived from the ERA5 reanalysis as the reference ASL index for the evaluation.

Over the 1979-2000 CE period, the ASL index from both the instrumental and paleo reconstructions displays a high correlation coefficient with ERA5 $(0.87$ (p-value $<0.05)$ and 0.65 (p-value $<0.05)$, respectively), as well as CE values (0.74 and 0.30, respectively; Fig. 4a). Although no estimation of the ASL index change exists over the last decades, Fogt et al. (2019) have recently provided a complete spatially reconstruction of Antarctic pressure back to 1905 $\mathrm{CE}$ at seasonal scale based on available pressure data from the Antarctic and the mid-latitudes of the Southern Hemisphere. It is worth noting that the goal of Fogt et al. (2019) was not to reconstruct the ASL variability over the past decades. Furthermore, Fogt et al. (2019) mention that their reconstruction has a poor skill in the Amundsen region mainly because of the sparse observational network in West Antarctica. In particular, prior to $1958 \mathrm{CE}$, this reconstruc- 
tion only relies on pressure observations situated in the mid-latitudes, and thus only depends on the mid latitudes-Antarctic connections. However, the comparison with Fogt et al. (2019) is still valuable since this is the only Antarctic pressure dataset based on instrumental observations available before $1979 \mathrm{CE}$. The ASL index derived from Fogt et al. (2019) displays a correlation coefficient $r$ of 0.75 (p-value $<0.05$ ) with ERA5 over 1979-2000 CE.
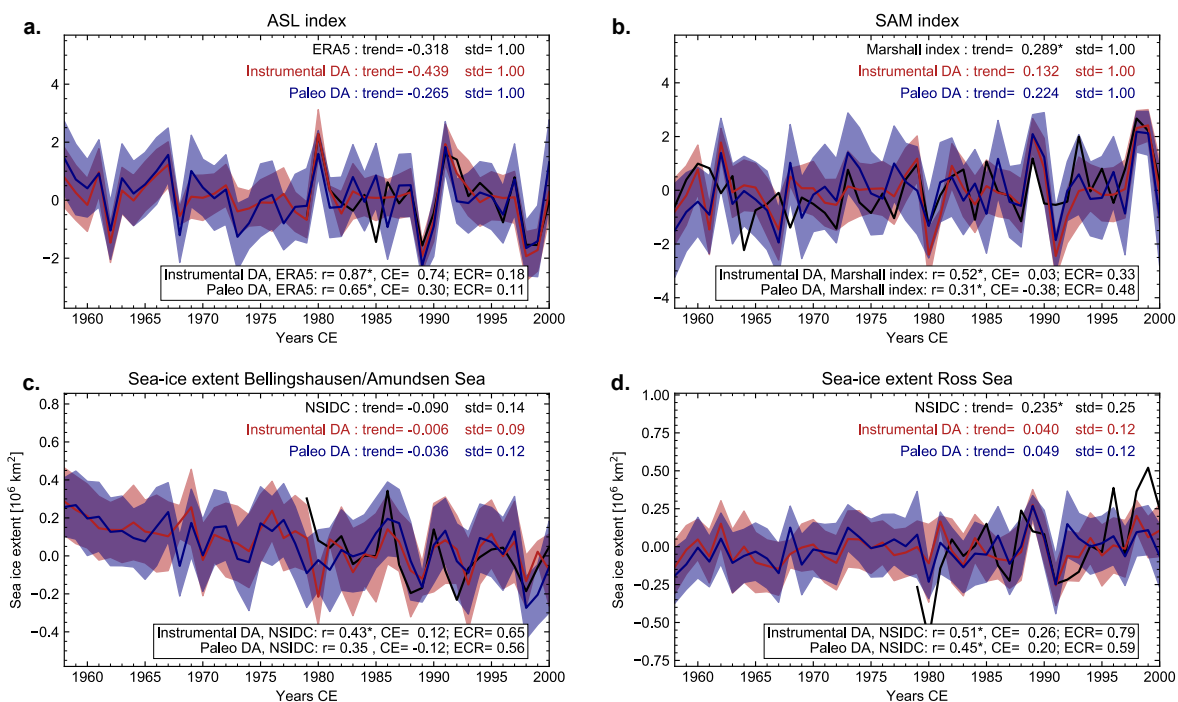

Fig. 4 (a) The Amundsen Sea Low (ASL) and (b) Southern Annular Mode (SAM; b) indexes derived from our instrumental (red) and paleo (blue) reconstructions correlated with ERA5 data (in black) for the ASL over 1979-2000 CE and the Marshall Index (Marshall 2003) (in black) for the SAM over 1958-2000 CE. For all the datasets plotted, the linear trends are displayed (expressed in decade ${ }^{-1}$ ) and the standard deviation (std) of the timeseries (unitless) over the 1979-2000 CE and 1958-2000 CE periods for the ASL and SAM, respectively. (c-d) Comparison between our instrumental (red) and paleo (blue) sea-ice extent $\left(10^{6} \mathrm{~km}^{2}\right)$ reconstructions (in anomalies) and the observed sea-ice extent from the National Snow and Ice Data Center (NSIDC; in black; only available from $1979 \mathrm{CE}$ ) for the Bellingshausen $/ \mathrm{Amundsen}$ Sea $\left(130^{\circ} \mathrm{W}-60^{\circ} \mathrm{W}\right)$ and Ross Sea $\left(160^{\circ} \mathrm{E}-130^{\circ} \mathrm{W}\right)$ sectors over the 1958-2000 CE period. Regional definitions are identical as in Parkinson (2019). Anomalies are computed over the 1979-2000 CE period. The linear sea-ice extent trends are displayed (expressed in $10^{6} \mathrm{~km}^{2}$ decade ${ }^{-1}$ ) and the standard deviation (std) of the timeseries (expressed in $10^{6} \mathrm{~km}^{2}$ ) over the 1979-2000 CE period for each region. Additionally, the correlation coefficient $(r)$, coefficient of efficiency (CE) and ensemble calibration ratio (ECR) are computed over the respective periods depending on the observations. Error bands correspond to the reconstruction uncertainty as defined in section 2.1. Our SAM index is computed as the normalized difference in mean sea-level pressure between the $40^{\circ} \mathrm{S}$ and $65^{\circ} \mathrm{S}$ longitude bands. Note that by construction, the standard deviation of all the SAM and ASL time-series are equal to 1.

Both our instrumental and paleo reconstructions are well correlated with the ASL index derived from Fogt et al. (2019) over 1979-2000 CE $(r=0.74(\mathrm{p}-$ value $<0.05)$ and 0.65 ( $\mathrm{p}$-value $<0.05)$, respectively), but correlation coefficients 
drop to 0.55 (p-value $<0.05)$ and 0.44 (p-value $<0.05)$ over 1958-2000 CE. This decrease is probably related to the smaller number of data (associated with a weaker quality) used in Fogt et al. (2019) during the 1958-1978 CE period since our observational network remains unchanged over 1958-2000 CE. Over the 1958-2000 CE period, the ASL index derived from Fogt et al. (2019) displays a linear trend of -0.12 std per decade ( $p$-value $>0.1$ ) while the trends from the instrumental and paleo reconstructions are -0.001 std per decade ( $\mathrm{p}$-value $>0.1$ ) and -0.17 std per decade ( $\mathrm{p}$-value $>0.1$ ), respectively. Our paleo-reconstruction is thus closer to Fogt et al. (2019) than our instrumental reconstruction. However, trends of the ASL index from Fogt et al. (2019) and our instrumental reconstruction are highly sensitive to the analyzed period, reflecting the high internal variability prevailing in this region (e.g., Raphael et al., 2016).

In addition to the ASL, we also analyze the main atmospheric mode of variability in the Southern Hemisphere, i.e., the Southern Annular Mode (SAM). SAM represents the intensity and position of the westerly winds. The SAM index (defined as the normalized difference in mean sea-level pressure between the $40^{\circ}$ and $65^{\circ}$ South longitude bands) derived from our instrumental reconstruction has a correlation coefficient $r$ of 0.52 (p-value $<0.05)$ with the Marshall index (Marshall, 2003) that is only based on atmospheric pressure observations (Fig. 4b). However, our instrumental reconstruction does not display the observed linear trend over 1958-2000 CE as in observations. On the contrary, our paleo-reconstruction is able to reconstruct the linear trend (albeit statistically insignificant) but the correlation coefficient drops to 0.31 (p-value $<0.05)$. The SAM being an annular mode, a high number of geographically evenly distributed observations is required to correctly reproduce this mode. This partly explains the limited skill of our SAM index since the observational network is unequally distributed geographically. Consequently, we mainly focus our analysis on the ASL and not on the SAM.

The best performance of our reconstructions for simulating the ASL compared to the SAM could be explained by two factors. The ASL is a more local atmospheric feature in comparison with the SAM. The observational network (instrumental and paleo observations) used in our reconstructions is limited to the Antarctic continent, with few records in East Antarctica, plus Tasmania, New Zealand and South America, which makes difficult to reconstruct the SAM. In contrast, our observational network includes a large number of records in West Antarctica, which is the region where the ASL has the largest influence. Additionally, the correlation coefficient between the SAM and ASL index in our paleo-reconstruction over the 1800-2000 CE period reaches 0.97 ( $\mathrm{p}$-value $<0.001$; non-sensitive to the analyzed period), meaning our reconstructed SAM variability mainly captures the ASL-related variability. Although our reconstruction seems to overestimate the ASL-SAM relationship, several studies have demonstrated that the ASL is highly correlated with the SAM in observations (Turner et al., 2013; Hosking et al., 2013; Raphael et al. 2016, Fogt and Marshall, 2020). 


\subsubsection{Sea-ice cover}

As for the atmospheric circulation, the sea-ice cover reconstructions rely totally on the relationships between the assimilated variables and sea-ice cover as represented by the model since this variable is not assimilated. Figure 2 shows that the sea-ice concentration from our instrumental reconstruction is well correlated with the observed sea-ice concentration from the National Snow and Ice Data Center (NSIDC) over the 1979-2000 CE period. This is especially true in the offshore regions where the interannual variability of the sea-ice concentration is the highest. Indeed, the ocean along the West Antarctic coast is nearly always covered by sea-ice (not shown). It is especially the case in the Ross Sea sector and to a lesser extent in the Amundsen Sea sector. This means that the interannual variability of the sea-ice concentration in this region is weak. Consequently, the sea-ice concentration in that region cannot explain the variability of the signal recorded in ice cores (e.g., snow accumulation and $\left.\delta^{18} \mathrm{O}\right)$. Therefore, given that the relationship between the ice core signal and sea-ice concentration in that region is weak, the sea-ice concentration in that region cannot be successfully reconstructed.

In order to quantify the sea-ice extent (i.e., oceanic surface covered by at least $15 \%$ of ice) at the regional scale, we divide the West Antarctic sector into two sectors following the geographical definitions of Parkinson (2019): the Bellingshausen/Amundsen Sea sector $\left(130^{\circ} \mathrm{W}-60^{\circ} \mathrm{E}\right)$ and Ross Sea sector $\left(160^{\circ} \mathrm{E}-130^{\circ} \mathrm{W}\right)$. It is important to stress that the overlapped period of 22 years between the NSIDC dataset and our reconstructions is short to evaluate in detail our sea-ice extent reconstruction. Therefore, this limits our ability to assess the quality of our reconstruction in terms of trends over the past decades.

Our instrumental reconstruction displays a correlation coefficient $r$ of 0.43 $(\mathrm{p}$-value $<0.05)$ and 0.51 ( $\mathrm{p}$-value $<0.05)$ with the NSIDC dataset over the 1979-2000 CE period for the Bellingshausen/Amundsen Sea and Ross Sea sectors, respectively (Fig. 4 4 ,d). Regarding our paleo-reconstruction, we observe an overall reduction of the local skill compared to our instrumental reconstruction (Fig. 2). However, our paleo-reconstruction still displays high correlation coefficients for both the Ross Sea and Bellingshausen/Amundsen Sea sectors when compared to the NSIDC dataset $(r=0.45$ ( $\mathrm{p}$-value $<0.05)$ and $r=0.35$ (p-value $>0.05)$, respectively; Fig. 4, $\mathrm{d}$ ). Additionally, the sea-ice extent for these two regions are highly correlated between the two reconstructions over the 1958-2000 CE period $(r=0.67$ ( $\mathrm{p}$-value $<0.05)$ and $r=0.56(\mathrm{p}$-value $<0.05)$, respectively; Fig. S4). Finally, both the instrumental and paleo reconstructions show a decrease in sea-ice extent for the Bellingshausen/Amundsen Sea sector over the 1958-2000 CE period (both $-0.05710^{6} \mathrm{~km}^{2}$ per decade; pvalue $<0.05)$, and an increase for the Ross Sea sector $\left(0.01810^{6} \mathrm{~km}^{2}\right.$ per decade ( $p$-value $>0.05$ ) and $0.02610^{6} \mathrm{~km}^{2}$ per decade ( $\mathrm{p}$-value $<0.05$ ), respectively for the instrumental and paleo-reconstruction). These changes over 1958-2000 CE are consistent with observations over the 1979-2000 CE period (Parkinson. 2019). However, although our instrumental and paleo reconstructions of the 
sea-ice extent are in agreement with observations regarding the direction of the change, our reconstructions underestimate the magnitude.

3.2 Reconstruction of the ASL and sea-ice in the West Antarctic sector over the last 200 years

Now that we have evaluated the skill of our reconstructions during the recent period, we can extend the reconstruction back in time. According to our annual paleo-reconstruction of the ASL index (Fig. 5), the ASL displays three main phases over the last two centuries. From $1800 \mathrm{CE}$ to around $1840 \mathrm{CE}$, we observe a positive linear trend (trend $=0.34$ std per decade; $p$-value $<0.001$ ) following by a period of about one century (until around $1940 \mathrm{CE}$ ) with virtually no trend (trend $=0.05$ std per decade; p-value $>0.05$ ). From around $1940 \mathrm{CE}$, the ASL displays a strong negative linear trend (trend $=-0.30$ std per decade; $\mathrm{p}$-value $<0.001$ ). This strong negative linear trend is consistent with the observed positive linear trend in the Southern Annular Mode, which deepens the ASL (e.g., Raphael et al., 2016). In addition to being stronger since $1940 \mathrm{CE}$, our results show that the ASL has also moved eastwards at the same time (Fig. S5; in our paleo-reconstruction, the longitudinal position of the ASL is anti-correlated with the ASL index over the 1800-2000 CE period; at $\mathrm{r}=-0.88$; $\mathrm{p}$-value $<0.001$ ) but no change in latitudinal position is noticed (not shown).

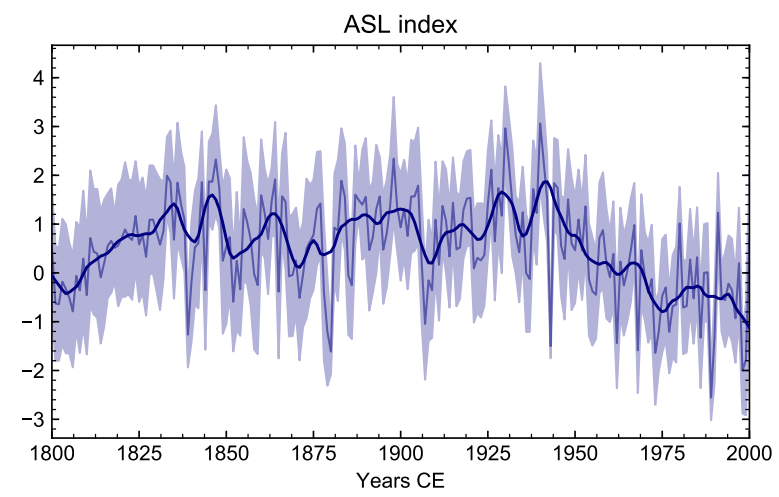

Fig. 5 ASL index derived from our paleo-reconstruction over 1800-2000 CE. Thin line corresponds to the annual index while the thick line is the decadal mean (10-year lowess smoothing). Error bands correspond to the reconstruction uncertainty as defined in section 2.1

Along with the ASL changes over the past two centuries, we analyze annual sea-ice extent changes in the West Antarctic sector, in particular in the Bellingshausen/Amundsen Sea sector $\left(130^{\circ} \mathrm{W}-60^{\circ} \mathrm{E}\right)$ and in the Ross Sea sector $\left(160^{\circ} \mathrm{E}-130^{\circ} \mathrm{W}\right.$; Fig. 6a,b). These two regions are anti-correlated at the annual scale in observations over 1979-2000 CE $(r=-0.26$ ( $\mathrm{p}$-value $>0.1)$. In our paleo- 
reconstruction, this correlation coefficient reaches $-0.50(\mathrm{p}$-value $<0.05)$ over the same period. However, our paleo-reconstruction indicates that this correlation coefficient varies over the past two centuries. In the Bellingshausen/Amundsen Sea sector, the sea-ice has grown from $1800 \mathrm{CE}$ to around $1860 \mathrm{CE}$ (trend $=0.037$ $10^{6} \mathrm{~km}^{2}$ per decade; $\mathrm{p}$-value $<0.001$ ) before starting a long-term reduction until present (trend $=-0.02110^{6} \mathrm{~km}^{2}$ per decade; p-value $<0.001$ ). On the contrary, the Ross Sea sector displays a different picture during the past two centuries. Over the first forty years of the $19^{\text {th }}$ century, our reconstruction indicates a reduction of the sea-ice extent in the Ross Sea sector (trend=-0.017 $10^{6} \mathrm{~km}^{2}$ per decade; p-value $>0.1$ ), which is followed afterwards by a slight long-term reduction of sea-ice extent until around $1940 \mathrm{CE}$ (trend $=-0.00910^{6} \mathrm{~km}^{2}$ per decade; p-value $<0.01)$. Finally, a positive linear trend is observed over the last sixty years (trend $=-0.02110^{6} \mathrm{~km}^{2}$ per decade; $\mathrm{p}$-value $<0.05$ ). Therefore, over the last two centuries, the only significant 50-year trend of sea-ice extent in the Ross Sea sector is the sea-ice expansion which has started from about 1940 CE.
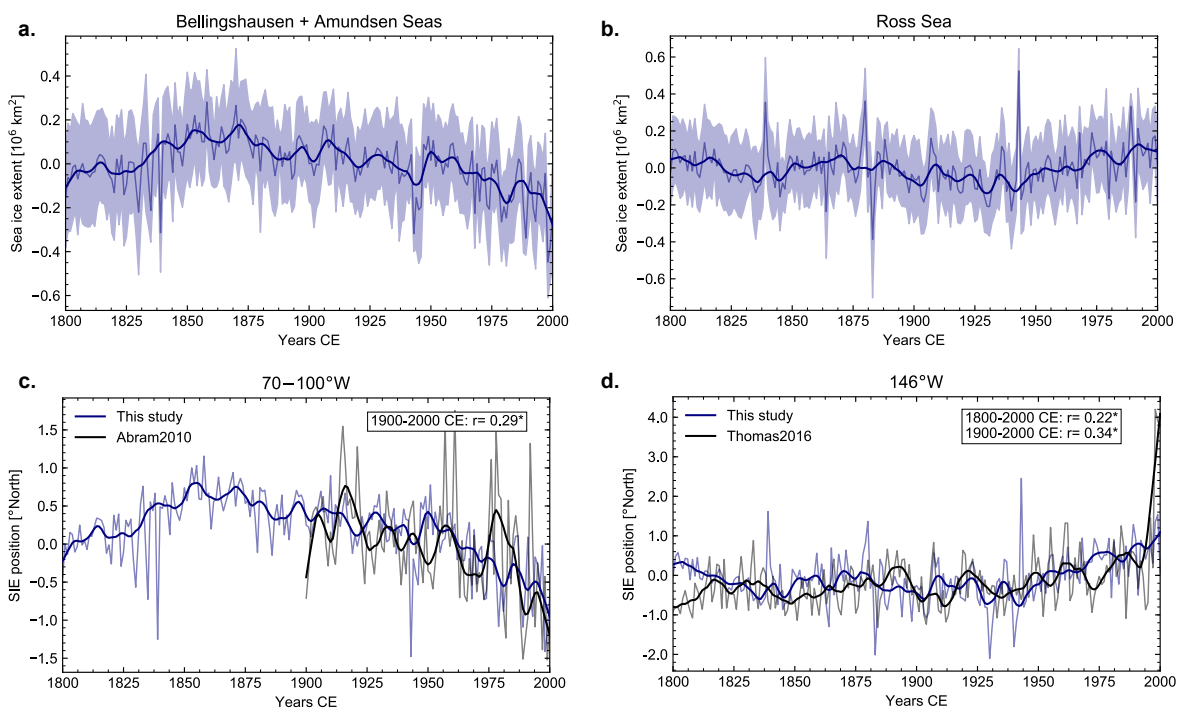

Fig. 6 Sea-ice extent for Bellingshausen/Amundsen Sea (a) and Ross Sea (b) sectors $\left(10^{6}\right.$ $\mathrm{km}^{2}$ ) derived from our paleo-reconstruction over 1800-2000 CE. Error bands correspond to the reconstruction uncertainty as defined in section 2.1 (c) Latitudinal position of the annual sea-ice extent edge averaged over $70-100^{\circ} \mathrm{W}$ in our paleo-reconstruction (in blue) and the MSA-based reconstruction of Abram et al. (2010) (in black) over 1800-2000 CE. (d) Latitudinal position of the annual sea-ice extent edge at $146^{\circ} \mathrm{W}$ in our paleo-reconstruction (in blue) and the MSA-based reconstruction of Thomas and Abram (2016) (in black) over 1800-2000 CE. Thin lines correspond to the annual reconstructions while thick lines are the decadal means (10-year lowess smoothing). For $(\mathbf{c})$ and $(\mathbf{d})$, correlation coefficients $(r)$ between the paleo and MSA-based reconstructions are computed over 1900-2000 CE (star indicates statistically significant correlation at the $95 \%$ confidence level). 
Our paleo sea-ice reconstructions can be compared to two independent reconstructions, which are based on phytoplankton productivity emissions from marine algae at the sea-ice edge (Methane Sulphonic Acid; hereafter MSA; Thomas et al., 2019). First, Thomas and Abram (2016) have reconstructed the position of the winter sea-ice edge at $146^{\circ} \mathrm{W}$ in the Amundsen-Ross sector since $1702 \mathrm{CE}$ using an ice core MSA record situated in West Antarctica. Over the 1800-2000 CE, the sea-ice edge at $146^{\circ} \mathrm{W}$ derived from our paleoreconstruction presents a correlation coefficient $r$ of $0.22(\mathrm{p}$-value $<0.05)$ with the MSA-based reconstruction from Thomas and Abram (2016) and 0.34 (pvalue $<0.05$ ) over the $1900-2000 \mathrm{CE}$ period (Fig. 6 d). Over the $20^{\text {th }}$ century, our reconstruction displays a sea-ice extent northward expansion of $0.13^{\circ}$ per decade, which is very similar to Thomas and Abram (2016) $\left(0.12 \pm 0.02^{\circ}\right.$ per decade). Therefore, although the interannual correlation is relatively low between both reconstructions, the long-term changes are consistent with each other. We also notice that our paleo-reconstruction is not able to reconstruct the exceptional sea-ice expansion for the 1997-1999 CE period (Hanna, 2001) in contrast with the MSA-based reconstruction from Thomas and Abram (2016).

The weaker agreement between two reconstructions at the interannual timescale is something to expect when comparing two very different paleo proxies. The MSA emissions arise from the algal blooms that occur in the spring, during the period of sea-ice break-up. Thus, this record is indicative of seasonal changes, closely linked to winter sea-ice extent, rather than annual sea-ice changes. The differences between the reconstructions can also partly be explained by the fact that the MSA record is influenced by conditions at the source as well as the transport pathways and potentially includes a non-climatic signal. In contrast, our data assimilation approach is unable to capture these small-scale local processes and, by construction, our method tends to minimize the non-climatic signal.

Second, using a similar methodology as Thomas and Abram (2016), Abram et al. (2010) have estimated a $-0.08 \pm 0.02^{\circ}$ per decade southward retreat in the Bellingshausen $/$ Amundsen Sea sector $\left(70^{\circ} \mathrm{W}-100^{\circ} \mathrm{W}\right)$ over the $1901-1990$ $\mathrm{CE}$ period, while our reconstruction suggests a slightly greater retreat $(-0.10$ - per decade; p-value $<0.05)$. Over the $20^{\text {th }}$ century, the correlation coefficient between the two reconstructions is 0.29 ( $\mathrm{p}$-value $<0.05$ ). Thus, despite the differences on the seasonal and inter-annual scale, our reconstruction independently confirms the long-term changes in sea-ice extent over the $20^{\text {th }}$ century as suggested by Thomas and Abram (2016), including the persistent dipole between the Bellingshausen/Amundsen Sea and Ross Sea sectors $(r=-0.70(p-v a l u e<0.001)$ in our reconstruction over 1900-1999 CE). However, our reconstruction indicates that the sea-ice extent retreat in the Bellingshausen/Amundsen Sea sector started around one century before the sea-ice extent expansion in the Ross Sea sector (Fig. 6a,b). 
The evolution of the sea-ice extent in the Ross Sea sector over the past two centuries coincides with the evolution of the ASL, with a correlation coefficient $r$ of -0.82 (p-value $<0.001)$ in our paleo-reconstruction. This confirms the dominant role of the ASL in modulating annual sea-ice variations in this sector, as highlighted by several studies (e.g., Hosking et al., 2013; Raphael and Hobbs, 2014, Raphael et al. 2019). The ASL has deepened (negative ASL index) over the past few decades, associated with enhanced cold southerly winds coming from the Ross Ice Shelf, resulting in sea-ice expansion in the Ross Sea sector (e.g., Lefebvre and Goosse, 2008). Conversely, when the ASL is deeper, this atmospheric situation tends to bring more warm air into the Bellingshausen/Amundsen Sea sector in concert with the horizontal movement of the sea-ice to the coast (i.e., ice compaction), which leads to a reduction of sea-ice cover.

However, the sea-ice variability in the Bellingshausen/Amundsen Sea sector is less correlated with the ASL index than for the Ross Sea sector in our reconstruction over the same period $(r=0.37$; p-value $<0.001)$. Additionally, unlike the Ross Sea sector, the correlation between the sea-ice extent and the ASL depends on the analyzed time period. For instance, this correlation coefficient drops to -0.16 ( $\mathrm{p}$-value $>0.1$ ) over 1851-1950 CE (against 0.37 over 1800-2000 CE (p-value $<0.001)$ ). During this period, the sea-ice extent for the Bellingshausen/Amundsen Sea sector is decreasing while the ASL index does not present a linear trend. This suggests that the ASL is not the unique driver controlling the variability of sea-ice extent in the Bellingshausen/Amundsen Sea sector. Raphael and Hobbs (2014) pointed out that the Zonal Wave Three and El-Nino Southern Ocean partly govern the variability of the sea-ice extent in the Bellingshausen/Amundsen Sea sector. Furthermore, the analysis of the spatial correlation coefficients between the sea-ice extent in the Bellingshausen/Amundsen Sea sector and the 500-hPa geopotential height based on our paleo-reconstruction (Fig. 7 a) indicates that the circulation changes along the Drake Passage (between Cape Horn and the South Shetland Islands) and in the Weddell Sea are correlated with the sea-ice extent in this region. This is confirmed by performing the same analysis with observations (NSIDC and ERA5) over 1979-2000 CE that also gives statistically significant correlation coefficients, but with smaller values (Fig. 7b). Nevertheless, the correlation coefficient between the sea-ice extent in the Bellingshausen/Amundsen Sea sector and the ASL over the 1951-2000 CE period reaches 0.66 (p-value $<0.001$; against -0.16 over $1851-1950 \mathrm{CE}$ ( $\mathrm{p}$-value $>0.1)$ ), pointing out the strong role of the ASL in the reduction of the sea-ice extent in this region over the last decades.

3.3 Is the current widespread warming over West Antarctica representative of changes in the past 200 years?

Numerous studies have pointed out a strong west-east asymmetry in the surface warming since $1958 \mathrm{CE}$ as West Antarctica has undergone a large 
Paleo DA-based reconstruction
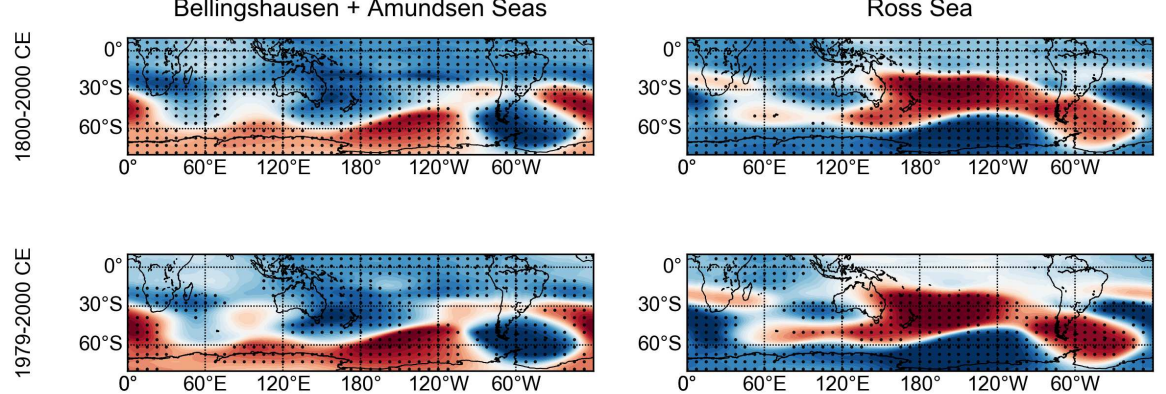

b.

Observations (ERA5/NSIDC)

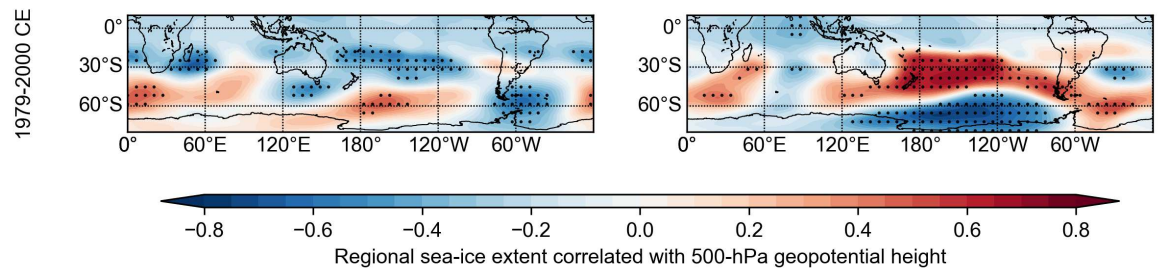

Fig. 7 (a) Annual sea-ice extent averaged over the Bellingshausen/Amundsen Sea and Ross Sea sectors correlated with the 500-hPa geopotential height in our paleo-reconstruction for the 1800-2000 CE and 1979-2000 CE periods. (b) As (a) but based on observations (ERA5 and NSIDC) over the 1979-2000 CE. Stippling indicates statistically significant correlations at the 95\% and 90\% confidence levels for the 1800-2000 CE and 1979-2000 CE periods, respectively.

widespread warming, unlike East Antarctica (e.g., Steig et al., 2009, Nicolas and Bromwich, 2014: Schneider et al., 2012, Jun et al., 2020). As a result, West Antarctica is often seen as a region that behaves homogeneously in terms of climate change and variability. However, it is still unknown if this observed widespread warming in West Antarctica over the past decades is representative of the behavior of the region on longer timescales. Our paleo-reconstruction allows examination of this representativeness by analyzing the near-surface air temperature changes over the past 200 years along with changes in other key variables such as snow accumulation, sea-ice extent and atmospheric circulation.

Figure 8 displays the linear trends for the 500-hPa geopotential height, 700-hPa air temperature, near-surface air temperature, snow accumulation and sea-ice concentration over 50-year periods between 1801 and $2000 \mathrm{CE}$. Over 1801-1850 CE, we observe a clear continental dipole in the trends of near-surface air temperature and snow accumulation between the Peninsula and a part of eastern WAIS compared to the western WAIS. The $500-\mathrm{hPa}$ geopotential height field shows that the ASL weakened during 1801-1850 CE (trend $=0.30$ std per decade; $p$-value $<0.01$ ), which is consistent with the time- 
series of the ASL index over the last two centuries (Fig. 5). These atmospheric conditions are associated with weaker northerly winds in the Peninsula that result in a cooling, while the opposite occurs in the western WAIS (i.e., the west of the WAIS Divide where the ice flow is null, which separates the WAIS into two regions). It has been shown that a strong positive correlation exists between temperature and snow accumulation over the Antarctic Ice Sheet (Frieler et al., 2015; Dalaiden et al., 2020a; Cavitte et al., 2020). Higher temperature induces an increase of the saturation vapor pressure that potentially leads to more continental precipitations (i.e., the Clausius-Clapeyron relationship). This is consistent with the cooling in the Peninsula (which corresponds to a snow accumulation decrease) and the warming in the western WAIS (which corresponds to a snow accumulation increase). In addition to the atmospheric circulation changes, continental changes are highly influenced by oceanic conditions (Kittel et al., 2018: Krinner et al., 2008). Particularly, when the ocean is ice-free, the air potentially contains more humidity because of the enhanced evaporation above the ocean. This eventually leads to a warming and an increase in snow accumulation over the continent when the airflow hits the coastline. Accordingly, we observe an increase in sea-ice concentration in the Bellingshausen/Amundsen Sea sector in contrast with a decrease in the Ross Sea sector.

During the second interval (i.e., 1851-1900 CE period), the continental and atmospheric circulation patterns are relatively similar to the one over the 1801$1850 \mathrm{CE}$ period. However, the amplitude of the surface changes is weaker and the ASL seems slightly shifted eastwards (Fig. 8). This induces an eastward shift of the warming pattern over the continent compared to the period 18011850 CE. Moreover, the typical dipole in sea-ice is no longer observed since a general reduction of the sea-ice extent is noticed in the West Antarctic sector. The 1901-1950 CE period is characterized by small and insignificant changes, except that a widespread sea-ice cover reduction is noticed as during the 1851$1900 \mathrm{CE}$ period. Over the last fifty years of the $20^{\text {th }}$ century, the atmospheric circulation corresponds almost to the opposite 1801-1850 CE pattern (Fig. 8). With a deepening ASL (trend=-0.22 std per decade; $p$-value $<0.01$ ), warmer and moister air is brought in the Peninsula resulting in a decrease of seaice cover in the Bellingshausen/Amundsen Sea sector, as well as a warming associated with an increase in snow accumulation in the Peninsula. As expected from the deeper ASL, the Ross Sea sector gained sea-ice during the same period while the western WAIS displays a decrease in snow accumulation. However, in contrast to the 1801-1850 CE period, the temperature change has the same sign over the whole West Antarctic region, in agreement with previous studies (e.g., Steig et al., 2009, Nicolas and Bromwich, 2014). The boundary between regions showing a warming and those displaying a cooling at 700-hPa is shifted offshore over the ocean while it was located close to the WAIS Divide for the period 1801-1850 (Fig. 8). The dipole is still present but the entire continent is experiencing a warming. The trends of $700-\mathrm{hPa}$ air temperature over 1951$2000 \mathrm{CE}$ on both sides of the Amundsen coasts are thus opposite. 

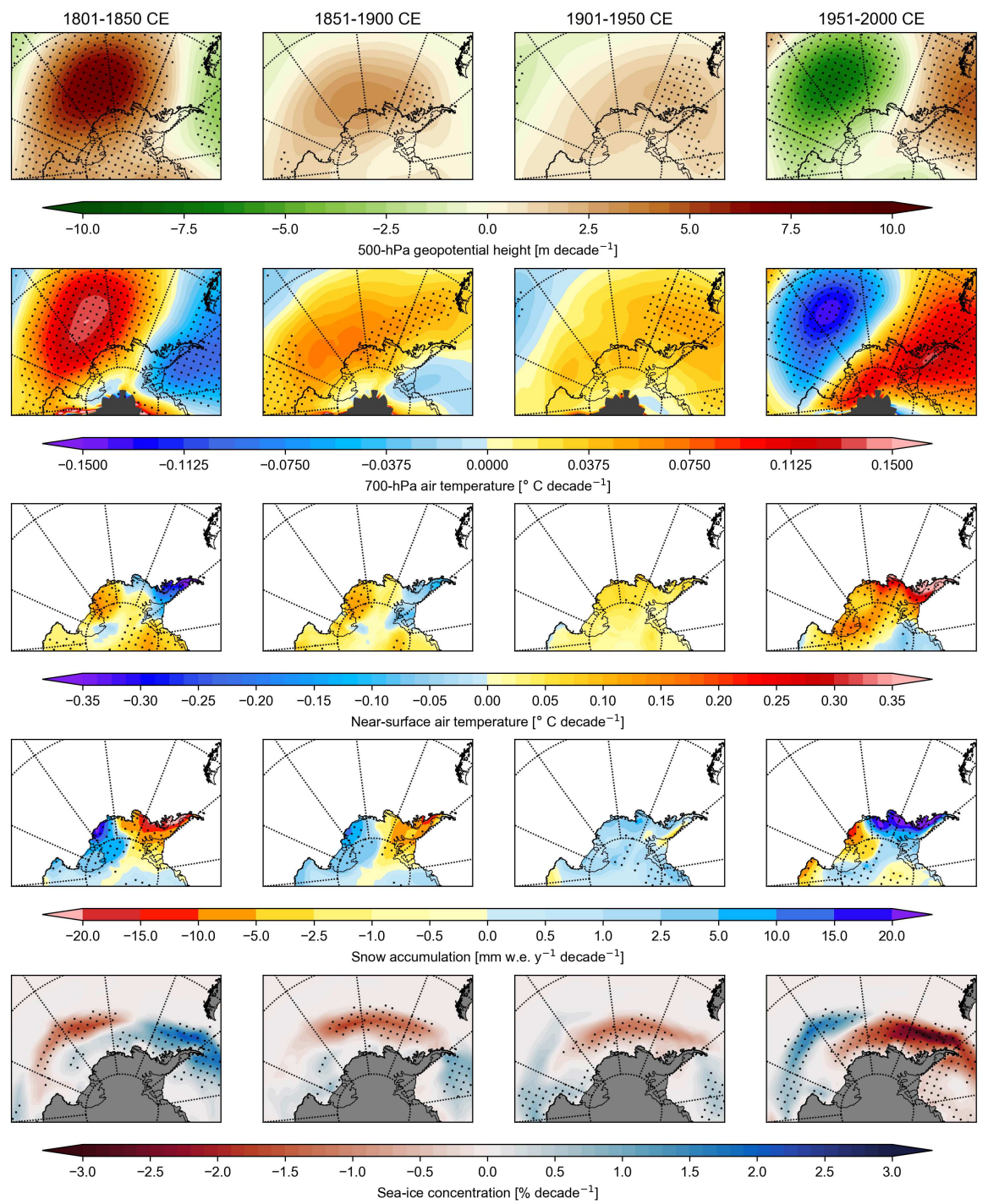

Fig. 8 Linear trends in 500-hPa geopotential height (m per decade), 700-hPa air temperature $\left({ }^{\circ} \mathrm{C}\right.$ per decade), near-surface air temperature $\left({ }^{\circ} \mathrm{C}\right.$ per decade), snow accumulation ( $\mathrm{mm}$ w.e. eq. year ${ }^{-1}$ par decade) and sea-ice cover (\% per decade) over the last 200 years separated by 50 -year intervals. Stippling indicates statistically significant correlations ( $95 \%$ confidence level). 
Since the change in the atmospheric circulation during this period roughly corresponds to the opposite pattern of the 1801-1850 CE period, the homogeneous warming over the continent could either indicate a change in the role of the ASL on the West Antarctic climate or a relationship between the ASL and the West Antarctic climate that may have changed over time. Figure 9 displays spatial correlation coefficients between the ASL index and near-surface air temperature, snow accumulation and 700-hPa air temperature over the 1801-1850 CE and 1951-2000 CE periods. Over the 1801-1850 CE period, the spatial patterns of correlation coefficients between the ASL index and the three variables are very similar to the spatial pattern of trends for the same variables and over the same period. This indicates that over that period, the ASL is the major contributor to those changes.

In contrast to the ASL-snow accumulation relationship, the relationship between the ASL and near-surface air temperature has changed between the two periods (Fig. 9). Correlation coefficients between the ASL index and nearsurface air temperature over 1951-2000 CE still exhibit a dipole like for the 1801-1850 CE period, but this dipole is shifted eastward. Additionally, the strength of the correlation over the western WAIS is weaker compared to the 1801-1850 CE period. This change in the link between the ASL and nearsurface air temperature could be related to a change in the mean state of the atmospheric circulation. According to our reconstruction and in agreement with previous studies, the atmospheric conditions prevailing in the Antarctic over 1951-2000 CE correspond to a positive phase of SAM in regards to the 1801-1850 CE period (Fig. 10). Based on the SAM index derived from our reconstruction and normalized over the 1800-2000 CE period, the SAM index averaged over $1801-1850 \mathrm{CE}$ is -0.11 against 0.87 over $1951-2000 \mathrm{CE}$.

To examine the role of the SAM in the relationship between the ASL and the near-surface air temperature and snow accumulation independently of our reconstruction, we analyze the relationships between the ASL and these two variables in the ERA5 reanalysis over 1979-2019 CE. More specifically, we perform the correlation of climate variables with the ASL index over negative SAM (SAM-) years compared with positive SAM $(\mathrm{SAM}+)$ years (Fig. 11). The analysis confirms that depending on the large-scale atmospheric background (i.e., the sign of the SAM index), the impact of the ASL on the near-surface air temperature and snow accumulation is different. During the SAM- years, the fingerprint of the ASL on the continent displays a clear dipole in both nearsurface air temperature and snow accumulation. During the SAM + years, the dipole in near-surface air temperature over the continent is much less clear with weaker correlation coefficients between the ASL and the near-surface air temperature in the western WAIS. This potentially indicates that snow accumulation is a better proxy for reconstructing the ASL than the nearsurface air temperature as shown in Thomas and Bracegirdle (2015).

As a consequence of the general warming in West Antarctica over the last 50 years, the western part of the region warms but has lower snow accumulation. This is opposite to the classical link between the two variables due to ClausiusClapeyron relationship. Cavitte et al. (2020) have shown that some areas over 


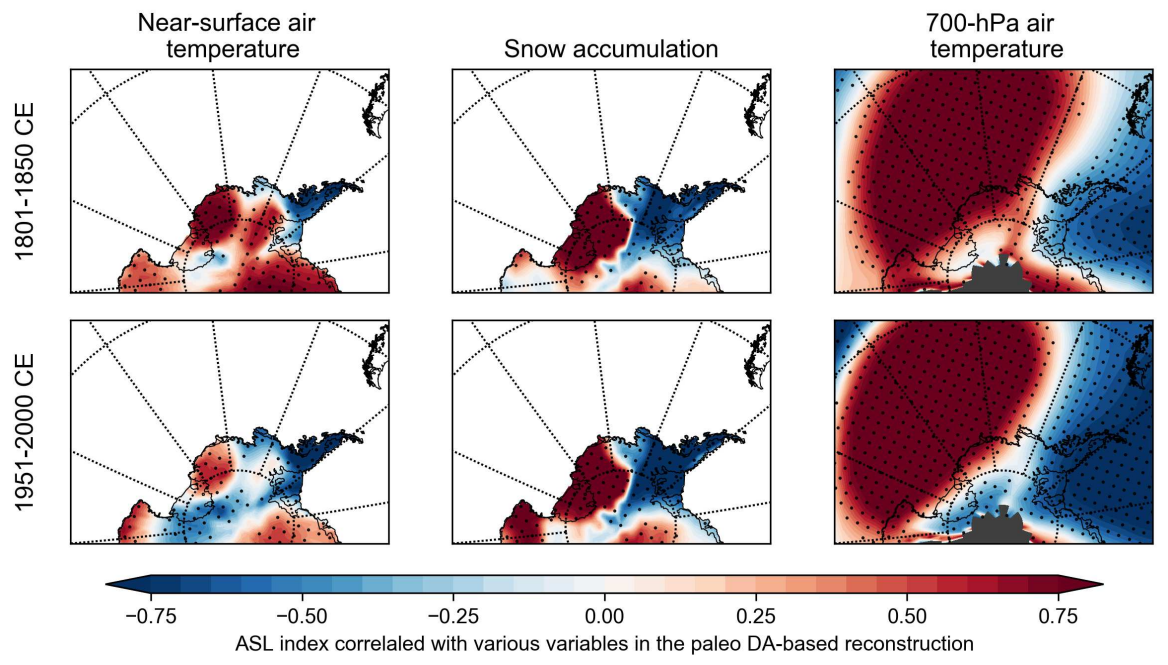

Fig. 9 Annual ASL index linearly correlated with near-surface air temperature, snow accumulation and $700-\mathrm{hPa}$ air temperature in our paleo-reconstruction for the 1801-1850 CE and 1951-2000 CE periods. Stippling indicates statistically significant correlations (95\% confidence level).

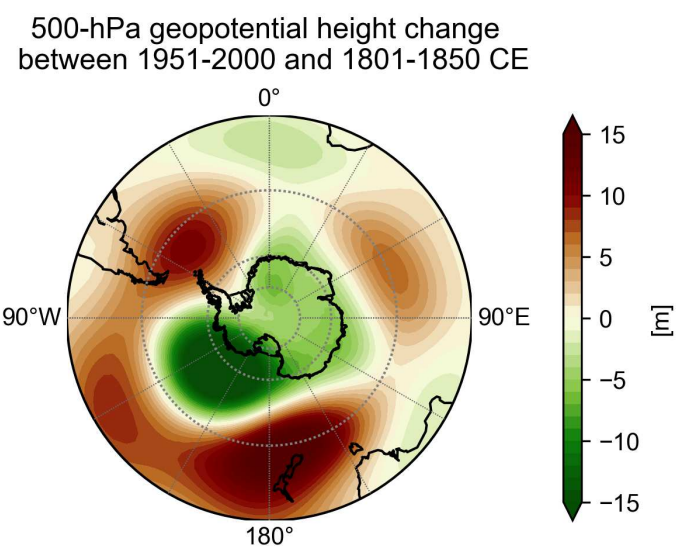

Fig. 10 Change in the 500-hPa geopotential height (m) between the 1951-2000 CE and 1801-1850 CE periods in our paleo-reconstruction.

the Antarctic continent in fact display a negative relationship between snow accumulation and near-surface air temperature because of winds-topography interactions. This is for instance observed over the Peninsula (Elvidge and Renfrew, 2016, Cavitte et al., 2020). We argue that the same phenomenon at larger spatial scale has occurred in WAIS during the 1951-2000 CE period because of the presence of the WAIS Divide. When warm moist air driven by the ASL is brought in the eastern WAIS towards the WAIS Divide, the 

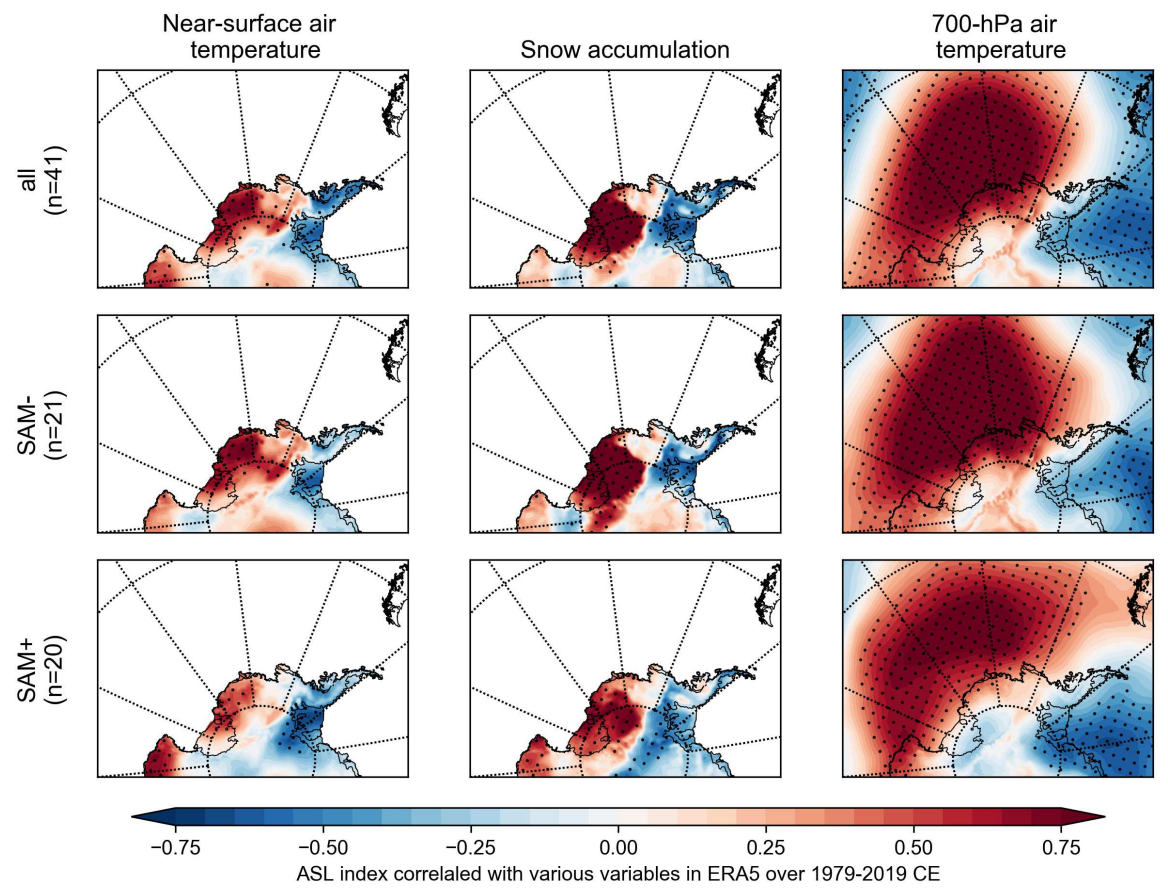

Fig. 11 Annual ASL index linearly correlated with near-surface air temperature, snow accumulation and 700-hPa air temperature in the ERA5 reanalysis over 1979-2019 CE. Correlations have been computed on all $(A l l), \mathrm{SAM}+(S A M+)$ or SAM- $(S A M-)$ years with $n$ corresponding to the sample length. Stippling indicates statistically significant correlations (90\% confidence level).

air moisture is released as snowfall during the uplift towards the Divide. At that point, the air masses start to descend towards the Ross Ice Shelf on the leeside. This results in an adiabatic warming, which is not associated with an increase in snow accumulation. However, this feature is mainly observed over the 1951-2000 CE period due to the position of the winds at that time (Figs. 8 and $\mathrm{S} 6)$.

\section{Conclusions}

In this paper, we have investigated the West Antarctic climate variability over the past two centuries by providing a complete reconstruction for the main atmospheric variables, as well as the sea-ice concentration. This is achieved by using a data assimilation approach that combines optimally the information brought by paleoclimate proxies and the climate physics from climate models. The reconstruction is based on all the annually-resolved snow accumulation and $\delta^{18} \mathrm{O}$ records from the Antarctic ice cores, as well as tree-ring width records situated in the mid-latitudes from the Southern Hemisphere. The use of the 
isotope-enable climate model iCESM1 in the data assimilation allows to avoid strong assumptions on the relationship between the $\delta^{18} \mathrm{O}$ in ice cores and climate variables.

We have evaluated our reconstruction using various independent data over the instrumental era and shown that our reconstruction is able to reproduce well the climate variability over West Antarctica (near-surface air temperature and snow accumulation), the atmospheric circulation in the West Antarctic sector (in particular, the ASL), and the sea-ice cover. Snow accumulation and $\delta^{18} \mathrm{O}$ records from ice cores, as well as tree-ring width, are thus providing valuable information to reconstruct the West Antarctic climate over the past 200 years at least. This is further confirmed by comparing our sea-ice extent reconstructions with two independent sea-ice reconstructions based on MSA records from ice cores, which leads to similar results as our reconstruction at the decadal scale.

According to our reconstruction, the overall observed reduction of seaice extent in the Bellingshausen/Amundsen Sea sector over the instrumental era (e.g., Parkinson, 2019) is part of a long-term linear trend starting at the beginning of the industrial period. In contrast, the increase of sea-ice extent in the Ross Sea sector has started one century later, around $1950 \mathrm{CE}$ and is preceded by a small sea-ice reduction between 1850 and $1950 \mathrm{CE}$. Our results show that the deeper ASL over the second half of the $20^{\text {th }}$ century generally explains these long-term changes by modulating winds in the West Antarctic sector. However, we observe that the strength of the relationship between the sea-ice extent in the Bellingshausen-Amundsen Sea sector and the ASL strongly varies over the past two centuries.

We have also shown that the observed general warming since $1958 \mathrm{CE}$ in West Antarctica is not representative of changes over the past 200 years, which usually present a dipole on the continent due to the ASL. Our reconstruction suggests that this widespread warming is explained by both the stronger ASL and the positive phase of SAM. Therefore, this could not be simply related to the fingerprint of the ASL impact on the continent or ocean surface, but also the SAM. The continental response to a change in the atmospheric circulation may not be stationary. Care must be thus taken when inferring changes at the West Antarctica-scale from local proxies. Care should also be taken when relying on the short instrumental period to infer changes in Antarctic climate variability and its drivers. Future climate scenarios are often reliant on our understanding of climate variability during the instrumental period. But our study demonstrates that this time period may not be the most representative of the climate variability over multi-decadal to centennial timescales.

Additionally, those time-dependent relationships, as well as the potential complex response of the climate in West Antarctica to the atmospheric circulation, raise concerns about simple statistical methods that assume, by construction, constant relationships between the proxy and the reconstructed climate variable. Using a more sophisticated method like data assimilation is a clear advantage because it directly relies on the covariance between the reconstructed variables and the observations as described by the model. Data 
assimilation-based reconstruction thus ensures that all reconstructed variables are dynamically consistent.

This present work is focused on the ongoing West Antarctic climate by analyzing local changes. Our study demonstrates that the recent period appears unusual in the longer context but further work is needed to understand the drivers and the underlying mechanisms of those changes. Atmospheric circulation changes in the high latitudes of the Southern Hemisphere over the past decades have been attributed to various factors (Thompson et al. 2011), most notably the atmospheric ozone depleting and the increase of the atmospheric greenhouse gases (e.g., Fogt et al., 2009, Polvani et al. 2011). Additionally, an increasing number of studies (e.g., Ding et al., 2011; Steig et al., 2013, Clem et al. 2016: Holland et al. 2019) have shown that changes in the West Antarctic climate are closely linked to the climate variability in the tropical Pacific and other basins through tropical-Antarctic teleconnections. These teleconnections influence the West Antarctic climate by modifying the atmospheric circulation around Antarctica. Therefore, quantifying the contribution of these teleconnections on the West Antarctic climate is a next step to improve the knowledge of the climate changes in West Antarctica over the past centuries.

Assimilating in addition tropical proxies (in particular corals; e.g., Tierney et al. 2015), would likely allow improving the reconstruction of the variability of the Antarctic climate by relying on the tropical-Antarctic teleconnections, particularly in the West Antarctic sector where they are known to be strong (e.g., Thomas et al., 2013, 2015). For instance, the tropical proxies could help to reproduce the exceptional sea-ice expansion in the Ross sector observed between 1997 and 1999 CE (e.g., Hanna, 2001) since this event has been largely attributed to tropical variability in the western Pacific Ocean. In addition, this new data assimilation-based reconstruction would provide a good framework to study the impact of tropical variability on the Antarctic climate over the past centuries.

Acknowledgements The resulting Antarctic climate reconstruction is available through zenodo (https://zenodo.org/record/4770179) or by request to Quentin Dalaiden (quentin.dalaiden@uclouvain.be). We would like to thank Ryan Fogt for the discussions on the ASL variability and its impact on the Antarctic climate. We thank Samantha Stevenson for her expertise on the outputs of iCESM1. We thank François Klein for his technical help for setting the data assimilation experiments and Marie G.P. Cavitte for her valuable comments on our study. We acknowledge the ECMWF and the NCAR for providing the ERA5 reanalysis and CESM model outputs, respectively. QD is a Research Fellow with the Fonds pour la formation à la Recherche dans l'Industrie et dans l'Agronomie (FRIA Belgium) and HG is research director within the F.R.S.-FNRS (Belgium). JR is a F.R.S-FNRS Research Fellow, Belgium (grant no. 1.A841.18). This work was partly supported by the Belgian Research Action through Interdisciplinary Networks (BRAIN-be) from Belgian Science Policy Office in the framework of the project "East Antarctic surface mass balance in the Anthropocene: observations and multiscale modelling (Mass2Ant)" (Contrat $\mathrm{n}^{\circ} \mathrm{BR} / 165 / \mathrm{A} 2 /$ Mass2Ant).

\section{Conflict of interest}

The authors declare that they have no conflict of interest. 


\section{References}

Abram NJ, Thomas ER, McConnell JR, Mulvaney R, Bracegirdle TJ, Sime LC, Aristarain AJ (2010) Ice core evidence for a 20th century decline of sea ice in the Bellingshausen Sea, Antarctica. Journal of Geophysical Research Atmospheres 115(23):1-9, DOI 10.1029/2010JD014644

Agosta C, Amory C, Kittel C, Orsi A, Favier V, Gallée H, Van Den Broeke MR, Lenaerts JT, Van Wessem JM, Van De Berg WJ, Fettweis X (2019) Estimation of the Antarctic surface mass balance using the regional climate model MAR (1979-2015) and identification of dominant processes. Cryosphere 13(1):281-296, DOI 10.5194/tc-13-281-2019

Badgeley JA, Steig EJ, Hakim GJ, Fudge TJ (2020) Greenland temperature and precipitation over the last 20,000 years using data assimilation. Climate of the Past 16:1335-1346, DOI https://doi.org/10.5194/cp-2019-164

Bracegirdle TJ (2013) Climatology and recent increase of westerly winds over the Amundsen Sea derived from six reanalyses. International Journal of Climatology 33(4):843-851, DOI 10.1002/joc.3473

Brady E, Stevenson S, Bailey D, Liu Z, Noone D, Nusbaumer J, Otto-Bliesner BL, Tabor C, Tomas R, Wong T, Zhang J, Zhu J (2019) The Connected Isotopic Water Cycle in the Community Earth System Model Version 1. Journal of Advances in Modeling Earth Systems 11(8):2547-2566, DOI 10.1029/2019MS001663

Brennan MK, Hakim GJ, Blanchard-Wrigglesworth E (2020) Arctic SeaIce Variability During the Instrumental Era. Geophysical Research Letters 47(7):1-9, DOI 10.1029/2019GL086843

Bromwich DH, Nicolas JP, Monaghan AJ, Lazzara MA, Keller LM, Weidner GA, Wilson AB (2013) Central West Antarctica among the most rapidly warming regions on Earth. Nature Geoscience 6(2):139-145, DOI 10.1038/ ngeo1671

Cavitte M, Dalaiden Q, Goosse H, Lenaerts J, Thomas E (2020) Reconciling the surface temperature-surface mass balance relationship in models and ice cores in Antarctica over the last two centuries. The Cryosphere 14:40834102, DOI 10.5194/tc-2020-36

Clem KR, Renwick JA, Mcgregor J, Fogt RL (2016) The relative influence of ENSO and SAM on Antarctic Peninsula climate. DOI 10.1038/175238c0

Dalaiden Q, Goosse H, Klein F, Lenaerts JTM, Holloway M, Sime L, Thomas ER (2020a) How useful is snow accumulation in reconstructing surface air temperature in antarctica? a study combining ice core records and climate models. The Cryosphere 14(4):1187-1207, DOI 10.5194/tc-14-1187-2020

Dalaiden Q, Goosse H, Lenaerts JT, Cavitte MG, Henderson N (2020b) Future Antarctic snow accumulation trend is dominated by atmospheric synopticscale events. Communications Earth \& Environment 1:1-9, DOI 10.1038/ s43247-020-00062-x

Ding Q, Steig EJ, Battisti DS, Küttel M (2011) Winter warming in West Antarctica caused by central tropical Pacific warming. Nature Geoscience 4(6):398-403, DOI 10.1038/ngeo1129 
Dotto TS, Naveira Garabato AC, Wåhlin AK, Bacon S, Holland PR, Kimura S, Tsamados M, Herraiz-Borreguero L, Kalén O, Jenkins A (2020) Control of the Oceanic Heat Content of the Getz-Dotson Trough, Antarctica, by the Amundsen Sea Low. Journal of Geophysical Research: Oceans 125(8), DOI 10.1029/2020JC016113

Dubinkina S, Goosse H, Sallaz-Damaz Y, Crespin E, Crucifix M (2011) Testing a Particle Filter To Reconstruct Climate Changes Over the Past Centuries. International Journal of Bifurcation and Chaos 21(12):3611-3618, DOI 10. $1142 / \mathrm{S} 0218127411030763$

Dufrêne E, Davi H, François C, le Maire G, Dantec VL, Granier A (2005) Modelling carbon and water cycles in a beech forest: Part I: Model description and uncertainty analysis on modelled NEE. Ecological Modelling 185(2):407-436, DOI https://doi.org/10.1016/j.ecolmodel.2005.01.004

Elvidge AD, Renfrew IA (2016) The causes of foehn warming in the lee of mountains. Bulletin of the American Meteorological Society 97(3):455-466, DOI 10.1175/BAMS-D-14-00194.1

Emile-Geay J, McKay NP, Kaufman DS, von Gunten L, Wang J, Anchukaitis KJ, Abram NJ, Addison JA, Curran MAJ, Evans MN, Henley BJ, Hao Z, Martrat B, McGregor HV, Neukom R, Pederson GT, Stenni B, Thirumalai K, Werner JP, Xu C, Divine DV, Dixon BC, Gergis J, Mundo IA, Nakatsuka T, Phipps SJ, Routson CC, Steig EJ, Tierney JE, Tyler JJ, Allen KJ, Bertler NAN, Björklund J, Chase BM, Chen MT, Cook E, de Jong R, DeLong KL, Dixon DA, Ekaykin AA, Ersek V, Filipsson HL, Francus P, Freund MB, Frezzotti M, Gaire NP, Gajewski K, Ge Q, Goosse H, Gornostaeva A, Grosjean M, Horiuchi K, Hormes A, Husum K, Isaksson E, Kandasamy S, Kawamura K, Kilbourne KH, Koç N, Leduc G, Linderholm HW, Lorrey AM, Mikhalenko V, Mortyn PG, Motoyama H, Moy AD, Mulvaney R, Munz PM, Nash DJ, Oerter H, Opel T, Orsi AJ, Ovchinnikov DV, Porter TJ, Roop HA, Saenger C, Sano M, Sauchyn D, Saunders KM, Seidenkrantz MS, Severi M, Shao X, Sicre MA, Sigl M, Sinclair K, St George S, St Jacques JM, Thamban M, Kuwar Thapa U, Thomas ER, Turney C, Uemura R, Viau AE, Vladimirova DO, Wahl ER, White JWC, Yu Z, Zinke J (2017) A global multiproxy database for temperature reconstructions of the Common Era. Scientific data 4(July):170088, DOI 10.1038/sdata.2017.88

England MR, Polvani LM, Smith KL, Landrum L, Holland MM (2016) Robust response of the Amundsen Sea Low to stratospheric ozone depletion. Geophysical Research Letters 43(15):8207-8213, DOI 10.1002/2016GL070055

Fan T, Deser C, Schneider D (2014) Recent Antarctic sea ice trends in the context of Southern Ocean surface climate variations since 1950. Geophysical Research Letters 41:2419-2426, DOI 10.1002/2014GL059239

Fisher DA, Reeh N, Clausen H (1985) Stratigraphic Noise in Time Series Derived from Ice Cores. Annals of Glaciology 7:76-83, DOI 10.3189/ s0260305500005942

Fogt RL, Marshall GJ (2020) The Southern Annular Mode: Variability, trends, and climate impacts across the Southern Hemisphere. WIREs Climate Change n/a(n/a):e652, DOI 10.1002/wcc.652 
Fogt RL, Perlwitz J, Monaghan AJ, Bromwich DH, Jones JM, Marshall GJ (2009) Historical SAM variability. Part II: Twentieth-century variability and trends from reconstructions, Observations, and the IPCC AR4 models. Journal of Climate 22(20):5346-5365, DOI 10.1175/2009JCLI2786.1

Fogt RL, Wovrosh AJ, Langen RA, Simmonds I (2012) The characteristic variability and connection to the underlying synoptic activity of the AmundsenBellingshausen Seas Low. Journal of Geophysical Research Atmospheres 117(7):1-22, DOI 10.1029/2011JD017337

Fogt RL, Schneider DP, Goergens CA, Jones JM, Clark LN, Garberoglio MJ (2019) Seasonal Antarctic pressure variability during the twentieth century from spatially complete reconstructions and CAM5 simulations. Climate Dynamics 53(3):1435-1452, DOI 10.1007/s00382-019-04674-8

Frieler K, Clark PU, He F, Buizert C, Reese R, Ligtenberg SR, Van Den Broeke MR, Winkelmann R, Levermann A (2015) Consistent evidence of increasing Antarctic accumulation with warming. Nature Climate Change 5(4):348-352, DOI 10.1038/nclimate2574

Fyke J, Lenaerts JT, Wang H (2017) Basin-scale heterogeneity in Antarctic precipitation and its impact on surface mass variability. Cryosphere 11(6):2595-2609, DOI 10.5194/tc-11-2595-2017

Goosse H, Lefebvre W, de Montety A, Crespin E, Orsi AH (2009) Consistent past half-century trends in the atmosphere, the sea ice and the ocean at high southern latitudes. Climate Dynamics 33(7-8):999-1016, DOI 10.1007/ s00382-008-0500-9

Goosse H, Crespin E, de Montety A, Mann ME, Renssen H, Timmermann A (2010) Reconstructing surface temperature changes over the past 600 years using climate model simulations with data assimilation. Journal of Geophysical Research 115(D9):D09108, DOI 10.1029/2009JD012737

Gossart A, Helsen S, Lenaerts JT, Vanden Broucke S, van Lipzig NP, Souverijns N (2019) An evaluation of surface climatology in state-of-the-art reanalyses over the Antarctic Ice Sheet. Journal of Climate 32(20):6899-6915, DOI 10.1175/JCLI-D-19-0030.1

Guiot J, Boucher E, Gea-Izquierdo G (2014) Process models and model-data fusion in dendroecology. Frontiers in Ecology and Evolution 2:52, DOI 10.3389 /fevo.2014.00052

Hakim GJ, Emile-Geay J, Steig EJ, Noone D, Anderson DM, Tardif R, Steiger N, Perkins WA (2016) The last millennium climate reanalysis project: Framework and first results. Journal of Geophysical Research 121(12):67456764, DOI 10.1002/2016JD024751

Hanna E (2001) Anomalous peak in antarctic sea-ice area, winter 1998, coincident with enso. Geophysical Research Letters 28(8):1595-1598, DOI https://doi.org/10.1029/2000GL012368

Hansen J, Ruedy M, Sato M, Lo K (2010) Global surface temperature change. Reviews of Geophysics 48:1-29, DOI 10.1029/2010RG000345.1

Hersbach H, Bell B, Berrisford P, Hirahara S, Horányi A, Muñoz-Sabater J, Nicolas J, Peubey C, Radu R, Schepers D, Simmons A, Soci C, Abdalla S, Abellan X, Balsamo G, Bechtold P, Biavati G, Bidlot J, Bonavita M, De 
Chiara G, Dahlgren P, Dee D, Diamantakis M, Dragani R, Flemming J, Forbes R, Fuentes M, Geer A, Haimberger L, Healy S, Hogan RJ, Hólm E, Janisková M, Keeley S, Laloyaux P, Lopez P, Lupu C, Radnoti G, de Rosnay P, Rozum I, Vamborg F, Villaume S, Thépaut JN (2020) The ERA5 global reanalysis. Quarterly Journal of the Royal Meteorological Society 146(730):1999-2049, DOI 10.1002/qj.3803

Holland PR, Bracegirdle TJ, Dutrieux P, Jenkins A, Steig EJ (2019) West Antarctic ice loss influenced by internal climate variability and anthropogenic forcing. Nature Geoscience DOI 10.1038/s41561-019-0420-9

Hosking JS, Orr A, Marshall GJ, Turner J, Phillips T (2013) The influence of the amundsen-bellingshausen seas low on the climate of West Antarctica and its representation in coupled climate model simulations. Journal of Climate 26(17):6633-6648, DOI 10.1175/JCLI-D-12-00813.1

Janjić T, Bormann N, Bocquet M, Carton JA, Cohn SE, Dance SL, Losa SN, Nichols NK, Potthast R, Waller JA, Weston P (2018) On the representation error in data assimilation. Quarterly Journal of the Royal Meteorological Society 144(713):1257-1278, DOI 10.1002/qj.3130

Jones JM, Gille ST, Goosse H, Abram NJ, Canziani PO, Charman DJ, Clem KR, Crosta X, De Lavergne C, Eisenman I, England MH, Fogt RL, Frankcombe LM, Marshall GJ, Masson-Delmotte V, Morrison AK, Orsi AJ, Raphael MN, Renwick JA, Schneider DP, Simpkins GR, Steig EJ, Stenni B, Swingedouw D, Vance TR (2016) Assessing recent trends in high-latitude Southern Hemisphere surface climate. Nature Climate Change 6(10):917926, DOI 10.1038/nclimate3103

Jones ME, Bromwich DH, Nicolas JP, Carrasco J, Plavcová E, Zou X, Wang SH (2019) Sixty Years of Widespread Warming in the Southern Midand High-Latitudes (1957-2016). Journal of Climate pp 6875-6898, DOI 10.1175/jcli-d-18-0565.1

Jun SY, Kim JH, Choi J, Kim SJ, Kim BM, An SI (2020) The internal origin of the west-east asymmetry of Antarctic climate change. Science Advances 6(24):1-9, DOI 10.1126/sciadv.aaz1490

Kittel C, Amory C, Agosta C, Delhasse A, Doutreloup S, Huot PV, Wyard C, Fichefet T, Fettweis X (2018) Sensitivity of the current Antarctic surface mass balance to sea surface conditions using MAR. Cryosphere 12(12):38273839, DOI $10.5194 /$ tc- $12-3827-2018$

Klein F, Abram NJ, Curran MAJ, Goosse H, Goursaud S, Masson-Delmotte V, Moy A, Neukom R, Orsi A, Sjolte J, Steiger N, Stenni B, Werner M (2019) Assessing the robustness of Antarctic temperature reconstructions over the past two millennia using pseudoproxy and data assimilation experiments. Climate of the Past 15:661-684, DOI 10.5194/cp-2018-90

Krinner G, Guicherd B, Ox K, Genthon C, Magand O (2008) Influence of oceanic boundary conditions in simulations of antarctic climate and surface mass balance change during the coming century. Journal of Climate 21(5):938-962, DOI 10.1175/2007JCLI1690.1

van Leeuwen PJ (2009) Particle Filtering in Geophysical Systems. Monthly Weather Review 137(12):4089-4114, DOI 10.1175/2009MWR2835.1 
Lefebvre W, Goosse H (2008) An analysis of the atmospheric processes driving the large-scale winter sea ice variability in the Southern Ocean. Journal of Geophysical Research: Oceans 113(2):1-15, DOI 10.1029/2006JC004032

Lenaerts JT, Vizcaino M, Fyke J, van Kampenhout L, van den Broeke MR (2016) Present-day and future Antarctic ice sheet climate and surface mass balance in the Community Earth System Model. Climate Dynamics 47(56):1367-1381, DOI 10.1007/s00382-015-2907-4

Lenaerts JT, Fyke JG, Medley B (2018) The signature of ozone depletion in recent Antarctic precipitation change: a study with the Community Earth System Model. Geophys Res Lett 45:12931- -12939, DOI 10.1029/2018GL078608

Lenaerts JTM, Ligtenberg SRM, Medley B, Van de Berg WJ, Konrad H, Nicolas JP, Van Wessem JM, Trusel LD, Mulvaney R, Tuckwell RJ, Hogg AE, Thomas ER (2017) Climate and surface mass balance of coastal West Antarctica resolved by regional climate modelling. Annals of Glaciology pp 1-13, DOI 10.1017/aog.2017.42

Mankoff KD, Jacobs SS, Tulaczyk SM, Stammerjohn SE (2012) The role of pine island glacier ice shelf basal channels in deep-water upwelling, polynyas and ocean circulation in pine island bay, antarctica. Annals of Glaciology 53(60):123-128, DOI 10.3189/2012AoG60A062

Marshall GJ (2003) Trends in the Southern Annular Mode from Observations and Reanalyses. Journal of Climate 16(1999):4134-4143, DOI 10.1175/1520-0442(2003)016<4134:TITSAM $>2.0$.CO;2

Matsikaris A, Widmann M, Jungclaus J (2015) On-line and off-line data assimilation in palaeoclimatology: A case study. Climate of the Past 11(1):81-93, DOI 10.5194/cp-11-81-2015

Medley B, Thomas ER (2019) Increased snowfall over the Antarctic Ice Sheet mitigated twentieth-century sea-level rise. Nature Climate Change 9(1):3439, DOI 10.1038/s41558-018-0356-x

Medley B, McConnell JR, Neumann TA, Reijmer CH, Chellman N, Sigl M, Kipfstuhl S (2018) Temperature and Snowfall in Western Queen Maud Land Increasing Faster Than Climate Model Projections. Geophysical Research Letters 45(3):1472-1480, DOI 10.1002/2017GL075992

Meehl GA, Arblaster JM, Bitz CM, Chung CT, Teng H (2016) Antarctic sea-ice expansion between 2000 and 2014 driven by tropical Pacific decadal climate variability. Nature Geoscience 9(8):590-595, DOI 10.1038/ngeo2751

Misson L (2004) MAIDEN: a model for analyzing ecosystem processes in dendroecology. Canadian Journal of Forest Research 34(4):874-887, DOI $10.1139 / \mathrm{x} 03-252$

Nash J, Sutcliffe J (1970) River flow forecasting through conceptual models part $\mathrm{i}$ - a discussion of principles. Journal of Hydrology 10(3):282 - 290, DOI https://doi.org/10.1016/0022-1694(70)90255-6

Nicolas JP, Bromwich DH (2011) Climate of West Antarctica and influence of marine air intrusions. Journal of Climate 24(1):49-67, DOI 10.1175/ 2010JCLI3522.1 
Nicolas JP, Bromwich DH (2014) New reconstruction of antarctic near-surface temperatures: Multidecadal trends and reliability of global reanalyses. Journal of Climate 27(21):8070-8093, DOI 10.1175/JCLI-D-13-00733.1

Oke PR, Sakov P (2008) Representation error of oceanic observations for data assimilation. Journal of Atmospheric and Oceanic Technology 25(6):10041017, DOI 10.1175/2007JTECHO558.1

PAGES2k Consortium, Ahmed M, Anchukaitis KJ, Asrat A, Borgaonkar HP, Braida M, Buckley BM, Büntgen U, Chase BM, Christie DA, Cook ER, Curran MAJ, Diaz HF, Esper J, Fan ZX, Gaire NP, Ge Q, Gergis J, GonzálezRouco JF, Goosse H, Grab SW, Graham N, Graham R, Grosjean M, Hanhijärvi ST, Kaufman DS, Kiefer T, Kimura K, Korhola AA, Krusic PJ, Lara A, Lézine AM, Ljungqvist FC, Lorrey AM, Luterbacher J, MassonDelmotte V, McCarroll D, McConnell JR, McKay NP, Morales MS, Moy AD, Mulvaney R, Mundo IA, Nakatsuka T, Nash DJ, Neukom R, Nicholson SE, Oerter H, Palmer JG, Phipps SJ, Prieto MR, Rivera A, Sano M, Severi M, Shanahan TM, Shao X, Shi F, Sigl M, Smerdon JE, Solomina ON, Steig EJ, Stenni B, Thamban M, Trouet V, Turney CSM, Umer M, van Ommen T, Verschuren D, Viau AE, Villalba R, Vinther BM, von Gunten L, Wagner S, Wahl ER, Wanner H, Werner JP, White JWC, Yasue K, Zorita E, Consortium $\mathrm{Pk}$ (2013) Continental-scale temperature variability during the past two millennia. Nature Geoscience 6(5):339-346, DOI 10.1038/ngeo1797

Parkinson CL (2019) A 40-y record reveals gradual Antarctic sea ice increases followed by decreases at rates far exceeding the rates seen in the Arctic. Proceedings of the National Academy of Sciences of the United States of America 116(29):14414-14423, DOI 10.1073/pnas.1906556116

Polvani LM, Waugh DW, Correa GJP, Son SW (2011) Stratospheric ozone depletion: The main driver of twentieth-century atmospheric circulation changes in the southern hemisphere. Journal of Climate 24(3):795 - 812, DOI 10.1175/2010JCLI3772.1

Pritchard HD, Ligtenberg SR, Fricker HA, Vaughan DG, Van Den Broeke MR, Padman L (2012) Antarctic ice-sheet loss driven by basal melting of ice shelves. Nature 484(7395):502-505, DOI 10.1038/nature10968

Raphael MN, Hobbs W (2014) The influence of the large-scale atmospheric circulation on antarctic sea ice during ice advance and retreat seasons. Geophysical Research Letters 41(14):5037-5045, DOI 10.1002/2014GL060365

Raphael MN, Marshall GJ, Turner J, Fogt RL, Schneider D, Dixon DA, Hosking JS, Jones JM, Hobbs WR (2016) The Amundsen sea low: Variability, change, and impact on Antarctic climate. Bulletin of the American Meteorological Society 97(1):111-121, DOI 10.1175/BAMS-D-14-00018.1

Raphael MN, Holland MM, Landrum L, Hobbs WR (2019) Links between the Amundsen Sea Low and sea ice in the Ross Sea: seasonal and interannual relationships. Climate Dynamics 52(3):2333-2349, DOI 10.1007/ s00382-018-4258-4

Rezsöhazy J, Goosse H, Guiot J, Gennaretti F, Boucher E, André F, Jonard M (2020) Application and evaluation of the dendroclimatic process-based model MAIDEN during the last century in Canada and Europe. Climate of 
the Past 16(3):1043-1059, DOI 10.5194/cp-16-1043-2020-supplement

Rignot E, Mouginot J, Scheuchl B, van den Broeke MR, van Wessem MJ, Morlighem M (2019) Four decades of Antarctic Ice Sheet mass balance from 1979-2017. Proceedings of the National Academy of Sciences pp 1-9, DOI 10.1073 pnas. 1812883116

Schneider DP, Deser C, Okumura Y (2012) An assessment and interpretation of the observed warming of West Antarctica in the austral spring. Climate Dynamics 38(1-2):323-347, DOI 10.1007/s00382-010-0985-x

Schneider U, Becker A, Finger P, Meyer-Christoffer A, Ziese M, Rudolf B (2014) GPCC's new land surface precipitation climatology based on qualitycontrolled in situ data and its role in quantifying the global water cycle. Theoretical and Applied Climatology 115(1-2):15-40, DOI 10.1007/ s00704-013-0860-x

Schwarz G (1978) Estimating the Dimension of a Model. Ann Statist 6(2):461464, DOI 10.1214/aos/1176344136

Sheffield J, Goteti G, Wood EF (2006) Development of a 50-yr high-resolution global dataset of meteorological forcings for land surface modeling. Journal of Climate 19(12):3088-3111

Shepherd A, Fricker HA, Farrell SL (2018) Trends and connections across the Antarctic cryosphere. Nature 558(7709):223-232, DOI 10.1038/ s41586-018-0171-6

Souverijns N, Gossart A, Gorodetskaya IV, Lhermitte S, Mangold A, Laffineur Q, Delcloo A, van Lipzig NPM (2018) How does the ice sheet surface mass balance relate to snowfall? insights from a ground-based precipitation radar in east antarctica. The Cryosphere 12(6):1987-2003, DOI $10.5194 /$ tc-12-1987-2018

Steig EJ, Schneider DP, Rutherford SD, Mann ME, Comiso JC, Shindell DT (2009) Warming of the Antarctic ice-sheet surface since the 1957 International Geophysical Year. Nature 457(7228):459-462, DOI 10.1038/ nature 07669

Steig EJ, Ding Q, White JWC, Küttel M, Rupper SB, Neumann TA, Neff PD, Gallant AJE, Mayewski PA, Taylor KC, Hoffmann G, Dixon DA, Schoenemann SW, Markle BR, Fudge TJ, Schneider DP, Schauer AJ, Teel RP, Vaughn BH, Burgener L, Williams J, Korotkikh E (2013) Recent climate and ice-sheet changes in West Antarctica compared with the past 2,000 years. Nature Geoscience 6:372-375, DOI 10.1038/NGEO1778

Steiger NJ, Steig EJ, Dee SG, Roe GH, Hakim GJ (2017) Climate reconstruction using data assimilation of water isotope ratios from ice cores. Journal of Geophysical Research: Atmospheres 122(3):1545-1568, DOI 10.1002/2016JD026011

Steiger NJ, Smerdon JE, Cook ER, Cook BI (2018) A reconstruction of global hydroclimate and dynamical variables over the Common Era. Scientific Data 5:1-15, DOI 10.1038/sdata.2018.86

Stenni B, Curran MA, Abram NJ, Orsi A, Goursaud S, Masson-Delmotte V, Neukom R, Goosse H, Divine D, Van Ommen T, Steig EJ, Dixon DA, Thomas ER, Bertler NA, Isaksson E, Ekaykin A, Werner M, Frezzotti M 
(2017) Antarctic climate variability on regional and continental scales over the last 2000 years. Climate of the Past 13(11):1609-1634, DOI 10.5194/ cp-13-1609-2017

Stevenson S, Otto-Bliesner BL, Brady EC, Nusbaumer J, Tabor C, Tomas R, Noone DC, Liu Z (2019) Volcanic Eruption Signatures in the IsotopeEnabled Last Millennium Ensemble. Paleoceanography and Paleoclimatology 34(8):1534-1552, DOI 10.1029/2019PA003625

Tardif R, Hakim GJ, Perkins WA, Horlick KA, Erb MP, Emile-Geay J, Anderson DM, Steig EJ, Noone D (2019) Last millennium reanalysis with an expanded proxy database and seasonal proxy modeling. Climate of the Past 15(4):1251-1273, DOI 10.5194/cp-15-1251-2019

Tetzner D, Thomas E, Allen C (2019) A validation of era5 reanalysis data in the southern antarctic peninsula - ellsworth land region, and its implications for ice core studies. Geosciences 9(7), DOI 10.3390/geosciences9070289

Thomas ER, Abram NJ (2016) Ice core reconstruction of sea ice change in the Amundsen-Ross Seas since 1702 A.D. Geophysical Research Letters 43(10):5309-5317, DOI 10.1002/2016GL068130

Thomas ER, Bracegirdle TJ (2015) Precipitation pathways for five new ice core sites in Ellsworth Land, West Antarctica. Climate Dynamics 44(7-8):20672078, DOI 10.1007/s00382-014-2213-6

Thomas ER, Marshall GJ, McConnell JR (2008) A doubling in snow accumulation in the western Antarctic Peninsula since 1850. Geophysical Research Letters 35(L01706):1-5, DOI 10.1029/2007GL032529

Thomas ER, Bracegirdle TJ, Turner J, Wolff EW (2013) A 308 year record of climate variability in West Antarctica. Geophysical Research Letters 40(20):5492-5496, DOI 10.1002/2013GL057782

Thomas ER, Hosking JS, Tuckwell RR, Warren RA, Ludlow EC (2015) Twentieth century increase in snowfall in coastal West Antarctica. Geophysical Research Letters 42(21):9387-9393, DOI 10.1002/2015GL065750

Thomas ER, Melchior Van Wessem J, Roberts J, Isaksson E, Schlosser E, Fudge TJ, Vallelonga P, Medley B, Lenaerts J, Bertler N, Van Den Broeke MR, Dixon DA, Frezzotti M, Stenni B, Curran M, Ekaykin AA (2017) Regional Antarctic snow accumulation over the past 1000 years. Climate of the Past 13(11):1491-1513, DOI 10.5194/cp-13-1491-2017

Thomas ER, Allen CS, Etourneau J, King ACF, Severi M, Winton VHL, Mueller J, Crosta X, Peck VL (2019) Antarctic Sea Ice Proxies from Marine and Ice Core Archives Suitable for Reconstructing Sea Ice over the past 2000 Years. Geosciences pp 1-33, DOI 10.3390/geosciences9120506

Thompson DWJ, Solomon S, Kushner PJ, England MH, Grise KM, Karoly DJ (2011) Signatures of the Antarctic ozone hole in Southern Hemisphere surface climate change. Nature Geoscience 4(11):741-749, DOI $10.1038 /$ ngeo1296

Tierney JE, Abram NJ, Anchukaitis KJ, Evans MN, Giry C, Kilbourne KH, Saenger CP, Wu HC, Zinke J (2015) Tropical sea surface temperatures for the past four centuries reconstructed from coral archives. Paleoceanography 30(3):226-252, DOI 10.1002/2014PA002717 
Turner J, Colwell SR, Marshall GJ, Lachlan-Cope TA, Carleton AM, Jones PD, Lagun V, Reid PA, Iagovkina S (2004) The SCAR READER project: Toward a high-quality database of mean Antarctic meteorological observations. Journal of Climate 17(14):2890-2898, DOI 10.1175/1520-0442(2004) $017<2890$ :TSRPTA $>2.0 . \mathrm{CO} ; 2$

Turner J, Colwell SR, Marshall GJ, Lachlan-Cope TA, Carleton AM, Jones PD, Lagun V, Reid PA, Iagovkina S (2005a) Antarctic climate change during the last 50 years. International Journal of Climatology 25(3):279-294, DOI https://doi.org/10.1002/joc.1130

Turner J, Lachlan-Cope T, Colwell S, Marshall GJ (2005b) A positive trend in western Antarctic Peninsula precipitation over the last 50 years reflecting regional and Antarctic-wide atmospheric circulation changes. Annals of Glaciology 41:85-91, DOI 10.3189/172756405781813177

Turner J, Phillips T, Hosking JS, Marshall GJ, Orr A (2013) The amundsen sea low. International Journal of Climatology 33(7):1818-1829, DOI 10.1002/ joc. 3558

Turner J, Orr A, Gudmundsson GH, Jenkins A, Bingham RG, Hillenbrand CD, Bracegirdle TJ (2017) Atmosphere-ocean-ice interactions in the Amundsen Sea Embayment, West Antarctica. Reviews of Geophysics 55(1):235-276, DOI 10.1002/2016RG000532

Turner J, Marshall GJ, Clem K, Colwell S, Phillips T, Lu H (2019) Antarctic temperature variability and change from station data. International Journal of Climatology (June):1-22, DOI 10.1002/joc.6378

Vaughan DG, Marshall GJ, Connolley WM, Parkinson C, Mulvaney R, Hodgson DA, King JC, Pudsey CJ, Turner J (2003) Recent rapid regional climate warming on the Antarctic Peninsula. Climatic Change 60(3):243-274, DOI 10.1023/A:1026021217991

Wang Y, Huai B, Thomas ER, Broeke MR, Wessem JM, Schlosser E (2019) A new 200-year spatial reconstruction of West Antarctic surface mass balance. Journal of Geophysical Research: Atmospheres 124:5282-5295, DOI $10.1029 / 2018 \mathrm{jd} 029601$

Watkins AJ, Mardia KV (1992) Maximum likelihood estimation and prediction mean square error in the spatial linear model. Journal of Applied Statistics 19(1):49-59, DOI 10.1080/02664769200000004

van Wessem JM, van de Berg WJ, Noël BPY, van Meijgaard E, Amory C, Birnbaum G, Jakobs CL, Krüger K, Lenaerts JTM, Lhermitte S, Ligtenberg SRM, Medley B, Reijmer CH, van Tricht K, Trusel LD, van Ulft LH, Wouters B, Wuite J, van den Broeke MR (2018) Modelling the climate and surface mass balance of polar ice sheets using racmo2 - part 2: Antarctica (1979-2016). The Cryosphere 12(4):1479-1498, DOI 10.5194/ tc-12-1479-2018 


\section{Supplementary Files}

This is a list of supplementary files associated with this preprint. Click to download.

- supp.pdf 